UMR 5824

93. chemin des Mouilles 69130 Ecully - France

Maison de IUniversité, Bâtiment $\mathrm{B}$ 10, rue Trefilerie 42023 Saint-Etienne cedex $02 \cdot$ France http://www.gate.cnrs.fr gate@gate.cnrs.fr

\title{
Health, wealth, and informality over the life cycle
} Julien Albertini, Xavier Fairise, Anthony Terriau

\begin{abstract}
:
How do labor market and health outcomes interact over the life cycle in a country characterized by a large informal sector and strong inequalities? To quantify the effects of bad health on labor market trajectories, wealth, and consumption, we develop a life-cycle heterogeneous agents model with a formal and an informal sector. We estimate our model using data from the National Income Dynamics Study, the first nationally representative panel study in South Africa. We run counterfactual experiments and show that health shocks have an important impact on wealth and consumption. The channel through which these shocks propagate strongly depends on the job status of individuals at the time of the shock. For formal workers, bad health reduces labor efficiency, which translates into lower earnings. For informal workers and the non-employed, the shock lowers the job finding rate and in- creases job separation into nonemployment, which results in a surge in non-employment spells. As bad health spells persist more for nonemployed than for employed individuals, the interaction between labor market risks and health risks generates a vicious circle.
\end{abstract}

\section{Keywords:}

Health, Wealth, Life cycle, Informality

\section{JEL codes:}

I14, I15 E26, O17, J46, J64

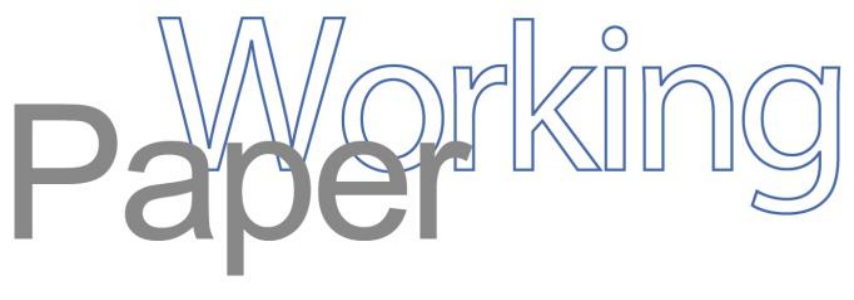




\title{
Health, wealth, and informality over the life cycle *
}

\author{
Julien Albertini ${ }^{\dagger} \quad$ Xavier Fairise $^{\ddagger} \quad$ Anthony Terriau ${ }^{\S}$
}

January 10, 2020

\begin{abstract}
How do labor market and health outcomes interact over the life cycle in a country characterized by a large informal sector and strong inequalities? To quantify the effects of bad health on labor market trajectories, wealth, and consumption, we develop a life-cycle heterogeneous agents model with a formal and an informal sector. We estimate our model using data from the National Income Dynamics Study, the first nationally representative panel study in South Africa. We run counterfactual experiments and show that health shocks have an important impact on wealth and consumption. The channel through which these shocks propagate strongly depends on the job status of individuals at the time of the shock. For formal workers, bad health reduces labor efficiency, which translates into lower earnings. For informal workers and the non-employed, the shock lowers the job finding rate and increases job separation into non-employment, which results in a surge in non-employment spells. As bad health spells persist more for nonemployed than for employed individuals, the interaction between labor market risks and health risks generates a vicious circle.
\end{abstract}

- JEL Classification: I14, I15 E26, O17, J46, J64

- Keywords: Health, Wealth, Life cycle, Informality

${ }^{*}$ We wish to thank Mariacristina De Nardi, Axelle Ferriere, Eric French, Izabella Jelovac, François Langot, Thepthida Sopraseuth, for their fruitful comments and suggestions. We also want to thank seminar and conference participants to the Workshop on health and heterogeneities in Lyon. This research was supported by Projet IDEX Impulsion Lyon Lumière 2. The usual disclaimer applies.

${ }^{\dagger}$ Univ Lyon, Université Lumière Lyon 2, GATE UMR 5824, F-69130 Ecully, France

${ }^{\ddagger}$ GAINS, University of Le Mans

${ }^{\S}$ GAINS, University of Le Mans 


\section{Introduction}

How do labor market and health outcomes interact over the life cycle in a country characterized by a large informal sector and strong inequalities? Unemployment is high in several developing countries, and the shadow economy encompasses a large share of employment (Schneider and Enste, 2000). Informal jobs, which are not under the purview of regulation, often have poor working conditions, pay lower wages, and involve an important labor market turnover. Several studies suggest that informal work may be detrimental to health (See Ludermir and Lewis (2003), Giatti et al. (2008), and López-Ruiz et al. (2015) for South and Central America; Alfers and Rogan (2015) for South Africa). Informal workers are exposed to airborne particles and handle hazardous products or machinery without proper protection, which leads to a higher prevalence of respiratory diseases and work injuries (Loewenson, 1998; Romero et al., 2010; Dike, 2019). Moreover, informal work may have damaging effects on mental health (Ludermir and Lewis, 2003; Ruiz et al., 2017).

In this study, we first show that in South Africa, informal workers have a higher probability of being unhealthy and of moving to non-employment than formal workers. In addition, non-employed individuals in bad health are less likely to find a job than their healthy counterparts. As bad health spells persist more for non-employed than for employed individuals, the interaction between labor market risks and health risks generates a vicious circle. Individuals facing recurrent spells of bad health are more likely to be excluded from the labor market and become trapped in poverty. If individuals are not perfectly insured against these risks, how costly is this health-wealth gradient? The originality of this study is that it uses a heterogeneous agent model to quantify the impact of health risks on wealth and consumption through their effect on labor market trajectories.

We focus on South Africa because it is one of the most unequal countries in the world. The poorest $50 \%$ of households account for only $8 \%$ of incomes and $4 \%$ of the net wealth, whereas the richest $10 \%$ of households own more than $55 \%$ of incomes and $71 \%$ of the net wealth (Hurlbut, 2018). In addition, almost half of the jobs are informal and approximately $60 \%$ of the working age population is non-employed. As in most developing countries, the unemployment benefits system is almost nonexistent, thereby exacerbating the impact of income risks. The strong economic inequalities and the poor performance of the labor market provide an interesting environment to evaluate the link between health and labor risks.

To quantify the impact of health risks, we first present some empirical facts concerning the labor market transitions, the survival probabilities, and 
the income and consumption profiles by health status using data from the National Income Dynamics Study (NIDS) ${ }^{1}$. We find that health status affects the transitions between employment and non-employment over the life cycle. Compared to formal workers, informal workers are more likely to experience bad health spells and to move to non-employment when unhealthy. The probability of finding a job declines sharply when an individual becomes unhealthy and state dependence is particularly important for informal workers and the non-employed. In addition, individuals in poor health have a lower income, face a shorter life expectancy, and have a higher (smaller) propensity to consume (save). All these channels affect the lifetime wealth gap between healthy and unhealthy individuals.

To quantify the respective contributions of the different channels, we develop a life-cycle heterogeneous agent model in line with Huggett (1996), where individuals face uninsured income and health risks (French (2005); De Nardi et al. (2017)). The model takes advantage of continuous-time techniques developed by Achdou et al. (2017) so that it reduces to a system of partial differential equations that can be solved efficiently and quickly. Economic agents can be employed (either in the formal sector or the informal sector) or non-employed. As in Aiyagari (1994), we assume that wealth takes the form of productive capital. Consistent with empirical evidence provided by La Porta and Shleifer (2008, 2014), we assume that firms operating in the formal sector use labor and capital as inputs in the production process whereas firms in the informal sector are less productive and use only labor. Formal workers receive higher wages but pay taxes. Changes in labor and health status as well as in the survival probability are represented by exogenous stochastic processes estimated using the NIDS data. We do not include any decision regarding private health expenditure ${ }^{2}$. We solve and estimate the model using the NIDS data. The model reproduces remarkably well several moments of the life-cycle profile of wealth in South Africa. The model generates wealth inequalities well within the range of those found in the data. Although it slightly underestimates the health-wealth gradient, it succeeds in accounting for the observed heterogeneities in the wealth evolution across job statuses.

We run counterfactual experiments to measure the lifetime costs of bad health in South Africa. We simulate what the path of wealth and consumption over the life cycle would have been if the probability of being in bad wealth was zero, other things being equal. We show that such a scenario

\footnotetext{
${ }^{1}$ The NIDS is a nationally representative panel study that surveys the same household members every two years.

${ }^{2}$ We explain this modeling choice below.
} 
would lead to an increase in wealth by more than $40 \%$ of the average formal wage. The decrease in consumption evaluated in terms of the average formal wage might reach $5 \%$. Importantly, the channel through which health risk propagates more strongly depends on the initial job status. Using an impulse response function analysis, we show that for formal workers, the bulk of variations in wealth and consumption caused by a one-period-long health shock is solely explained by income losses. As these workers' labor efficiency declines, their wage falls and so does their wealth. For informal workers and the non-employed, the shock mainly translates into labor market probabilities. In the informal sector, job separation into non-employment rise and the probability of finding a job declines substantially for the nonemployed. As a consequence, the surge in non-employment duration causes the shock to be highly persistent. For instance, for formal workers, it takes 12 years to compensate for half of the impact of the shock. This duration is approximately 20 years for informal workers and more than 30 years for the non-employed. Our results illustrate the poverty trap in which informal workers and non-employed fall when affected by health shocks.

The remainder of this paper is organized as follows: Section 2 presents our data, details the empirical strategy used to estimate the transition matrices and life-cycle profiles, and provides some empirical facts on South Africa. Section 3 develops the life-cycle heterogeneous agent model. Section 4 presents the estimation of the model and the numerical simulations. Section 5 summarizes our findings and concludes.

\section{Data}

The NIDS is the first national household panel study in South Africa. NIDS provides detailed information on various topics, such as employment status, income, wealth, and health. The study began in 2008 and continues to collect data from the same household members every two years. In the present study, we use the first five waves of NIDS.

Five major features characterize the South African labor market. First, two-thirds of the working age population are non-employed. Second, there are nearly as many individuals working in the formal sector as in the informal sector $^{3}$. Third, the system of unemployment benefits is almost nonexistent ${ }^{4}$.

\footnotetext{
${ }^{3}$ Among employed workers, we distinguish between those who pay social contributions (formal workers) from those who do not (informal workers). Throughout the study, we exclude self-employed workers and focus on salaried workers.

${ }^{4}$ The average income replacement rate is very low compared to international standards $(<50 \%)$. Moreover, due to stringent requirements and restrictions, less than $15 \%$ of the
} 
Fourth, the average monthly wage is much higher in the formal sector than in the informal sector. Fifth, there is strong state dependence ${ }^{5}$ among the three employment states (formal employment, informal employment, and non-employment). Individuals who are most distant from the labor market have greater difficulty in escaping non-employment and finding a formal job, which plunges some people into poverty.

The South African healthcare system is also of particular interest. Although health expenditure (as a percentage of GDP) lies at the average for OECD countries, out-of-pocket expenses (as a percentage of health spending) are the lowest in the world, even lower than those in France or in Luxembourg (Source: OECD). After the end of apartheid, the right to obtain healthcare was enshrined in the Constitution of the Republic of South Africa. A free primary healthcare policy was implemented, first for women and children, and then for all citizens. The amount of financial and human resources devoted to healthcare has risen considerably over the past two decades. Currently, approximately $90 \%$ of health services are provided through the public sector, with only some wealthy families preferring to obtain care from private clinics formerly reserved for white people.

\section{$2.1 \quad$ Health measure}

Health is a complex and multidimensional concept that can be measured in many ways. On the one hand, objective health measures have the advantage of being based on a medical diagnosis, but only provide a partial picture of an individual's health. On the other hand, alternative health measures, such as self-reported health, have the drawback of being subjective, but provide an overall indication of an individual's health. Self-reported health is often used in the literature as a proxy for health status (Frijters et al., 2005; Jones and Schurer, 2011). Although it is a subjective health measure, several studies have shown that self-rated health is highly correlated with objective health outcomes and physicians' ratings (LaRue et al., 1979; Okun et al., 1984; Connelly et al., 1989; Idler and Angel, 1990; McCallum et al., 1994; Grant et al., 1995; Idler and Kasl, 1995; Lundberg and Manderbacka, 1996; Idler and Benyamini, 1997; Burström and Fredlund, 2001; Franks et al., 2003). Moreover, self-reported health has significant explanatory power in predicting survival probability (Van Doorslaer and Gerdtham, 2003; Pijoan-Mas and Ríos-Rull, 2014) and is a better predictor of mortality than several objective health measures (Mossey and Shapiro, 1982). In our study, we use self-

unemployed receive unemployment benefits, and approximately $7 \%$ of the non-employed.

${ }^{5}$ See Subsection 2.2 for a discussion on state dependence. 
assessed health (SAH) to define an individual's health status. SAH refers to the question "How would you describe your health at present?" with five answer categories: 5 ("Excellent"), 4 ("Very good"), $\mathbf{3}$ ("Good"), 2 ("Fair"), and 1 ("Poor"). In this study, we regard an individual as being in "bad health" if he or she reports that his or her health is "Poor" or "Fair", and as being in "good health" if he or she states that his or her health is "Good", "Very good", or "Excellent".

\subsection{Estimation of life-cycle transition matrices}

We assume that, in each period, each individual is in one of the following states: Formal work-Good health $(z=1)$, Formal work-Bad health $(z=2)$, Informal work-Good health $(z=3)$, Informal work-Bad health $(z=4)$, Nonemployment-Good health $(z=5)$, Non-employment-Bad health $(z=6)$. The probability of being in a given state depends on the observed individual and household characteristics (observed heterogeneity), on unobserved characteristics and preferences (unobserved heterogeneity), and on the lagged state $z$ (state dependence). To analyze the mobility patterns among the six states and to distinguish heterogeneity from state dependence, we estimate a dynamic multinomial logit model with random effects, similar to the one used by Gong et al. (2004).

Using the terminology of Gong et al. (2004), we define the utility of state $z$ in period $p>1$ as follows:

$$
V(m, z, p)=X_{m p}^{\prime} \Upsilon_{z}+\zeta_{m p}^{\prime} \gamma_{z}+\vartheta_{m z}+\epsilon_{m z p}
$$

where $X_{m p}$ is a vector of explanatory variables including age, education, race, marital status, number of household members, and period dummies. $\zeta_{m p}$ is a vector of dummies representing the lagged states. In this sense, $\zeta_{m p}$ captures the state dependence (Heckman, 1981), that is, the direct effect that experiencing a certain situation in $p-1$ has on the probability of experiencing the same situation in $p . \vartheta_{m z}$ is a random effect, representing an unobserved individual-specific and time-invariant component. We also assume that the $\epsilon_{m z p}$ have a Type 1 extreme value (Gumbel) distribution and are independent of the $X_{m p}$ and $\vartheta_{m z}$. For identification purposes, $\Upsilon_{1}, \gamma_{1}$, and $\vartheta_{m 1}$ are normalized to zero. Consequently, the probability for individual $m$ to be in state $z$ in period $p>1$, given the observed characteristics $X_{m p}$, lagged state dummies $\zeta_{m p}$, and the random effect $\vartheta_{m}=\vartheta_{m 1}, \vartheta_{m 2}, \vartheta_{m 3}, \vartheta_{m 4}, \vartheta_{m 5}, \vartheta_{m 6}$, is given by:

$$
P\left(z \mid X_{m p}, \zeta_{m p}, \vartheta_{m}\right)=\frac{\exp \left(X_{m p}^{\prime} \Upsilon_{z}+\zeta_{m p}^{\prime} \gamma_{z}+\vartheta_{m z}\right)}{\sum_{s=1}^{6} \exp \left(X_{m p}^{\prime} \Upsilon_{s}+\zeta_{m p}^{\prime} \gamma_{s}+\vartheta_{m s}\right)}
$$


We use the procedure suggested by Heckman (1981) to address the initial condition problem. For $p=1$, we estimate a static multinomial logit model, excluding $\zeta_{m p}$, which contains the lagged values of the dependent variables. The utility of state $z$ in period $p=1$ can be written as:

$$
V(m, z, 1)=X_{m 1}^{\prime} \pi_{z}+\theta_{m z}+\epsilon_{m z 1}
$$

where $\pi_{z}$ is a vector of parameters and $\theta_{m z}$ is a random effect. The probability for individual $m$ to be in state $z$ in period $p=1$, conditional on $X_{m 1}$ and $\theta_{m}=\theta_{m 1}, \theta_{m 2}, \theta_{m 3}, \theta_{m 4}, \theta_{m 5}, \theta_{m 6}$, is given by:

$$
P_{1}\left(z \mid X_{m 1}, \theta_{m}\right)=\frac{\exp \left(X_{m 1}^{\prime} \pi_{z}+\theta_{m z}\right)}{\sum_{s=1}^{6} \exp \left(X_{m 1}^{\prime} \pi_{s}+\theta_{m s}\right)}
$$

To identify the model, $\pi_{1}$ and $\theta_{m 1}$ are normalized to zero. Estimates of the model parameters are obtained by maximum simulated likelihood, following the estimation procedure by Gong et al. (2004).

Table 1 displays the odds ratio effects for the median profile to simplify the interpretation of the estimates. The results provide strong evidence of state dependence. All the coefficients on the diagonal exceed 1, which means that individuals in state $z$ in period $p-1$ are more likely to be in the same state in the following period, compared to the reference state. For example, a non-employed individual in bad health in $p-1$, compared to a formal worker in good health, is, ceteris paribus, 74 times more likely to remain non-employed and in bad health in $p$. An interesting feature is that state dependence is particularly strong for informal workers and, a fortiori, for the non-employed. This phenomenon intensifies if the individual is in bad health. The results also provide evidence that poor health reduces the likelihood of employment. All these elements suggest that some people are "trapped" in poverty or bad health. When these two factors are combined, upward mobility becomes extremely difficult. 
Table 1: Transition model (Odd-ratios)

\begin{tabular}{|c|c|c|c|c|c|}
\hline \multirow[b]{2}{*}{ State $_{p-1}$} & \multicolumn{5}{|c|}{ State $_{p}$} \\
\hline & $\begin{array}{c}(2) \\
\text { Formal work } \\
\text { Bad health }\end{array}$ & $\begin{array}{c}(3) \\
\text { Informal work } \\
\text { Good health }\end{array}$ & $\begin{array}{c}(4) \\
\text { Informal work } \\
\text { Bad health }\end{array}$ & $\begin{array}{c}(5) \\
\text { Non-emp. } \\
\text { Good health }\end{array}$ & $\begin{array}{c}(6) \\
\text { Non-emp. } \\
\text { Bad health }\end{array}$ \\
\hline (1) Formal work-Good health & Ref. & Ref. & Ref. & Ref. & Ref. \\
\hline (2) Formal work-Bad health & 1.117 & 0.996 & 1.665 & 0.907 & 0.354 \\
\hline (3) Informal work-Good health & 0.472 & $5.335^{* * *}$ & $7.334^{* * *}$ & $4.579^{* * *}$ & 1.091 \\
\hline (4) Informal work-Bad health & 0.854 & $6.585^{* * *}$ & $6.599^{* * *}$ & $3.672^{* *}$ & $6.274^{* * *}$ \\
\hline (5) Non-emp.-Good health & 1.226 & $5.726^{* * *}$ & $8.199^{* * *}$ & $23.209^{* * *}$ & $26.413^{* * *}$ \\
\hline (6) Non-emp.-Bad health & 1.865 & $11.322^{* * *}$ & $23.681^{* * *}$ & $44.066^{* * *}$ & $74.175^{* * *}$ \\
\hline \multicolumn{6}{|c|}{$\begin{array}{l}\text { Interpretation: Compared to a formal worker in good health in } p-1 \text {, a non-employed individual in bad health in } p-1 \text {, is, ceteris paribus, } \\
74 \text { times more likely to be non-employed and in bad health in } p \text {, rather than employed in the formal sector and in good health } \\
\text { Reference state: Formal work-Good health } \\
\text { Significance: } 10 \%(*), 5 \%(* *) \text {, and } 1 \%(* * *) \\
\text { NIDS (five waves), individuals aged between } 15 \text { and } 60\end{array}$} \\
\hline
\end{tabular}

We then compute transition probabilities between states for given combinations of characteristics. The benchmark individuals have completed their compulsory education (grade 9), are black, married, and live in a household consisting six members. We then use the model predictions for each age group to determine the life-cycle transition probabilities (Figure 1). 
Figure 1: Life-cycle transition probabilities

(a) Formal exit rate

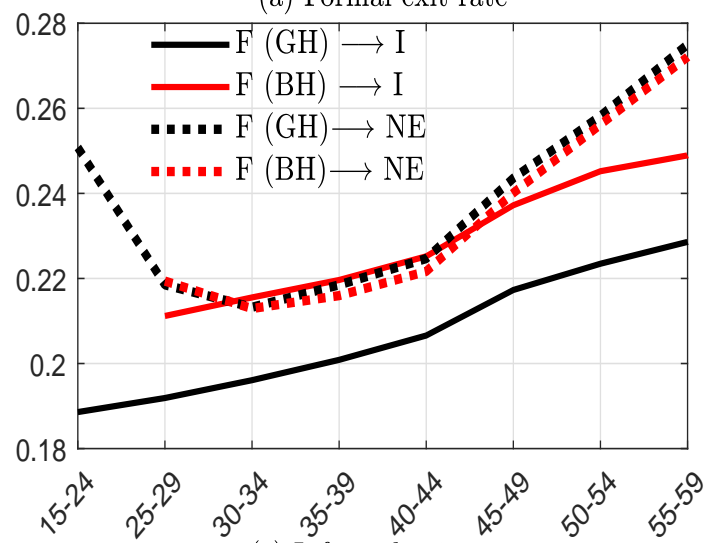

(c) Informal exit rate

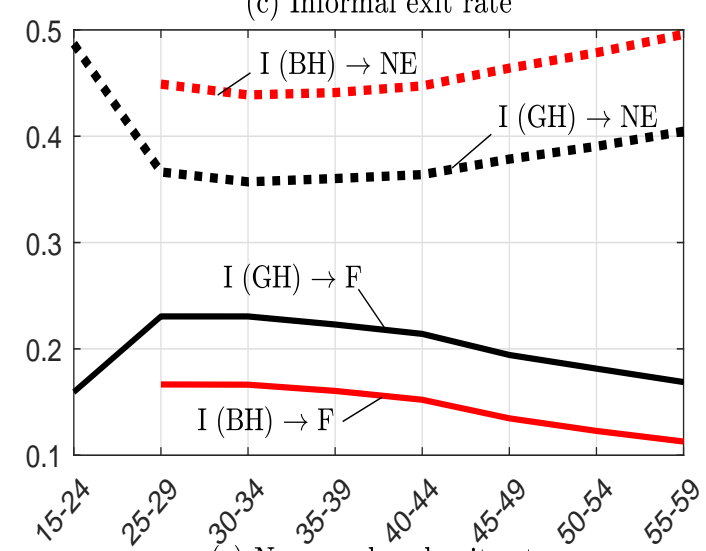

(e) Non-employed exit rate

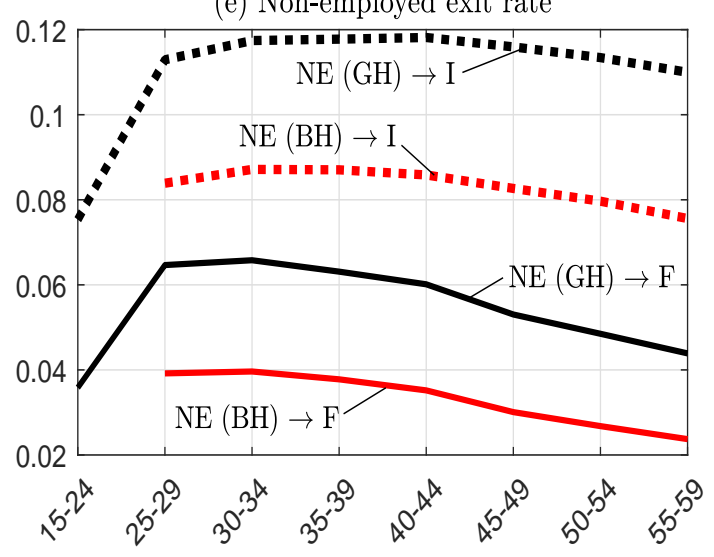

(b) Formal health change

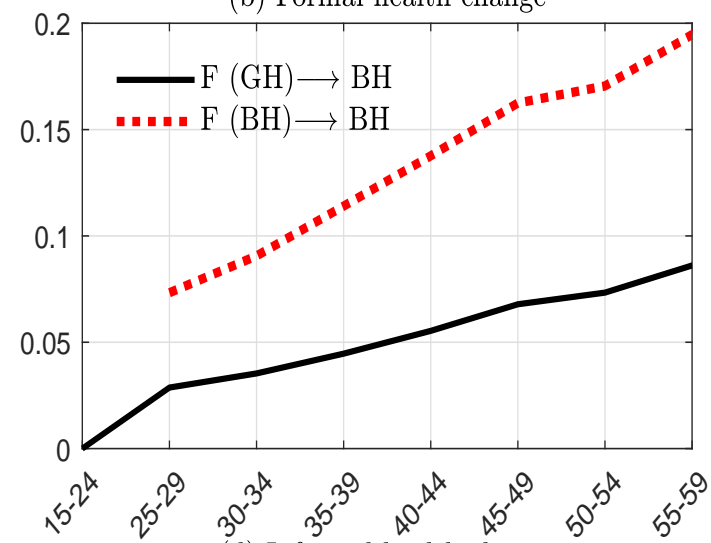

(d) Informal health change

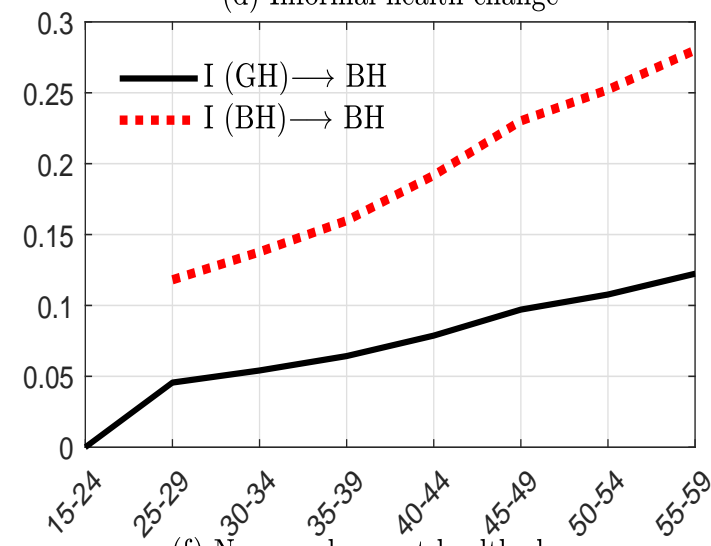

(f) Non-employment health change

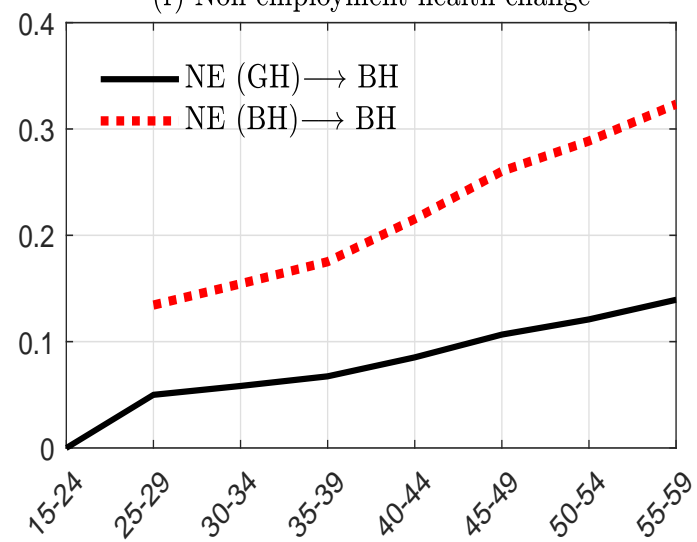

F: Formal. I: Informal. N: Non-employed. GH: Good health. BH: Bad health.

Health and labor market trajectories interact across the life-cycle in the 
following way: Formal workers hit by a health shock have a higher probability of moving to the informal sector in the following period (panel (a)). Once employed in the informal sector, unhealthy workers are more likely to become non-employed than healthy ones (panel (c)). Lastly, the job finding rate of the non-employed is extremely low, particularly for people in poor health (panel (e)). Meanwhile, the right panels of Figure 1 show that health exhibits strong persistence: the probability of being in bad health in the following period is much higher among unhealthy individuals, in particular if they are employed in the informal sector and, a fortiori, if they are in the pool of non-employed individuals. On average, the non-employed in poor health have a $90 \%$ chance of staying in the same state in the following period. To summarize, informal workers are more likely to be unhealthy than formal workers and there is strong state dependence in the bad health status. Since the chances of moving out of non-employment fall substantially for unhealthy individuals, the two-sided interactions between health and labor market outcomes lead to some people being trapped in poor health and poverty.

\subsection{Estimation of life-cycle profiles}

In this section, we describe how the life-cycle profiles for (net) wages and wealth are constructed. To take into account the individual-specific heterogeneity, we estimate a panel data model with random effects ${ }^{6}$. First, we estimate the following equation:

$$
\Lambda_{m p}=\varsigma+\varrho \chi_{m p}+u_{m p}+\varphi_{m p}
$$

where $\Lambda_{m p}$ represents an observation for wages, income, or wealth; $u_{m p}$ is the between-entity error term; and $\varphi_{m p}$ is the within-entity error term. Our methodology is similar to that of French (2005) and De Nardi et al. (2017). In vector $\chi$, we include individual characteristics (education, race, marital status, and number of household residents) but also a full set of interaction terms between age dummy variables, health status dummy variables and labor force status dummy variables. Lastly, we use age effects, health status effects, and labor force status effects to generate the life-cycle profiles by considering, as earlier, that benchmark individuals have completed their compulsory education (grade 9), are black, married, and live in a household consisting six members (median profile). The generated life-cycle profiles represent the empirical counterparts of the simulated profiles generated by the model described in Section 3.

\footnotetext{
${ }^{6}$ The Hausmann test suggests that the use of random effects is appropriate.
} 


\subsection{Health-wealth nexus}

As already mentioned, a free primary healthcare system was established in South Africa in the late 1990s, so out-of-pocket expenses are close to zero among poorer households. However, some individuals, particularly the richest ones, turn towards private clinics and have positive out-of-pocket expenses. A key question is whether these individual medical expenses affect their health. For instance, this would be the case if private clinics provide better patient care than public hospitals.

Albertini and Terriau (2019c) use an instrumental variable strategy to assess the impact of wealth on health in South Africa. They estimate a two-stage probit model with inheritance as an instrumental variable for the change in wealth and show that an increase in wealth has no significant impact on health. This result is confirmed by Albertini and Terriau (2019b), who estimate a dynamic bivariate probit model with initial conditions to disentangle the sources of the health-wealth gradient in South Africa. They show that the health-wealth gradient is mainly driven by the effects of health on wealth, and not vice versa.

In our model, we follow the aforementioned empirical studies by assuming that wealth does not have any direct impact on health but that health can impact wealth through affecting incomes and labor market trajectories.

\subsection{Time preference}

As highlighted by Venti and Wise (2000) and Hendricks (2007b), the main challenge for life-cycle models is to generate wealth dispersion among households with similar lifetime earnings. Several studies suggest that much of the variation in wealth accumulation over the life-cycle can be explained by the heterogeneity in households' rate of time preferences (Krusell and Smith, 1998; Samwick, 1998; Hendricks, 2007a). As indicated by De Nardi et al. (2017), the wealth gap between the healthy and the unhealthy is much higher than that implied by the differences in lifetime earnings and life expectancy. This suggests that the healthy and the unhealthy have very different propensities to consume. To test this assumption, we estimate a panel data model with random effects with household expenditure as the dependent variable. The set of explanatory variables includes education, race, marital status, number of household residents, household income, and household net wealth. Our results confirm that, all other things being equal, the unhealthy have a higher propensity to consume than the healthy ${ }^{7}$. As in De Nardi

\footnotetext{
${ }^{7}$ The difference is significant at the $1 \%$ level. This result is robust to many alternative specifications.
} 
et al. (2017), to capture this heterogeneity in time preferences, we introduce a health-dependent discount factor in our model.

\section{Model}

We consider an overlapping-generations model with heterogeneous agents, similar to Aiyagari (1994) and Huggett (1996), where individuals face income and health risks. We consider a three-state labor market status: employed in the formal sector, employed in the informal sector, and non-employed. The model is written in continuous time as in Achdou et al. (2017).

\subsection{Individual agents}

The economy is populated by a continuum of finitely lived households of mass 1 . We assume that up to age $t^{\star}=60$, individuals are either employed (in the formal or informal sector) or non-employed and retire at age $60^{8}$. A household is characterized by a health status $h \in \mathcal{H}=\{g, b\}$, where $g$ stands for good and $b$ for bad. Before age $t^{\star}$, individuals are characterized by an employment status $j \in \mathcal{J}=\{f, i, u\}$, where $f$ stands for formal employment, $i$ for informal employment, and $u$ for non-employment. After age $t^{\star}$, all individuals are retired, so $j \in \mathcal{J}=\{d\}$ (where $d$ stands for retirement). We assume that a change in job status and health status occurs simultaneously. Let us define

$$
\mathcal{Z}=\mathcal{J} \times \mathcal{H}= \begin{cases}\{(f, g),(f, b),(i, g),(i, b),(u, g),(u, b)\} & \text { if } t \leq t^{\star} \\ \{(d, g),(d, b)\} & \text { if } t>t^{\star}\end{cases}
$$

The probability of staying in state $z$ between $t$ and $t+d t$ can be written as $e^{-\lambda(z, z, t) d t}=1-\lambda(z, z, t) d t$; the probability of moving to state $z^{\prime}$ can be written as $1-e^{-\lambda\left(z, z^{\prime}, t\right) d t}=\lambda\left(z, z^{\prime}, t\right) d t$. One has $\lambda(z, z, t)=\sum_{z^{\prime} \in \mathcal{Z}, z^{\prime} \neq z} \lambda\left(z, z^{\prime}, t\right)$. Since the term $\lambda\left(z, z^{\prime}, t\right)$ depends on $t$, this expression for the transition probabilities takes into account the two distinct periods: before and after the retirement age $t^{*}$

Before age $t^{\star}$, workers receive an income that depends on age and job health status. Consider an employed worker. He or she offers a quantity of (efficient) labor $\ell(z, t)$, which is job and age dependent. The efficiency of an employed worker grows with age and depends on the job health status. The

\footnotetext{
${ }^{8}$ In South Africa, a flat-rate old-age pension is paid to people aged 60 or older. Only $25 \%$ of the population reach retirement age with a funded pension benefit. Consequently, the old-age grant is the main source of income for $75 \%$ of the elderly population.
} 
age dependency captures the average impact of experience and human capital accumulation on efficiency at work and on the wages observed in the data (see, e.g., Burdett et al. (2011), Bagger et al. (2014), Albertini and Terriau (2019a)). We consider the following functional form for labor efficiency:

$$
\log (\ell(z, t))=\log \left(\eta_{0}^{z}\right)+\eta_{1}^{z} \log (t)
$$

where $\eta_{x}^{z}, x=1,2$ are parameters that govern the shape of wage growth over the life-cycle. Provided that $0<\eta_{1}^{z}<1$, the experience profile of the wage is increasing and concave. $\eta_{0}^{z}$ and $\eta_{1}^{z}$ are estimated to reproduce the life-cycle profile of wages. For one unit of efficient labor, a worker is paid $w_{j}$, so that the labor income of an agent (of age $t$ and in state $z$ ) is given by $w_{j} \ell(z, t)$.

Non-employed workers are assumed to receive an income $b$ from home production that does not depend on age or health status ${ }^{9}$. Retired individuals receive a (lump sum) public retirement pension $\bar{p}$. This retirement pension does not depend on health or on working experience ${ }^{10}$.

We denote by $y(z, t)$ the net income of an individual with job health status $z$ at age $t$. When employed in the formal sector, the individual's net income is $y((f, h), t)=(1-\tau) w_{f} \ell((f, h), t)$, where $w_{f}$ is the wage rate in the formal sector and $\tau$ is the income tax rate. In the informal sector, the income is $y((i, h), t)=w_{i} \ell(i, h, t)$, where $w_{i}$ is the wage rate in the informal sector $^{11}$. If the worker is non-employed, the income is $y((u, h), t)=b$ and if he is retired, $y((u, h), t)=\bar{p}$.

We denote by $a$ the household wealth. The agent is subject to the following resources constraints:

$$
\begin{aligned}
& \dot{a}(t)=y(z, t)+(1-\tau \times 1\{a(t) \geq 0\}) r a(t)-c(t)+\bar{\tau} \\
& r \underline{a}+y(z, t)+\bar{\tau}-c(t) \geq 0
\end{aligned}
$$

where $r$ is the real interest rate. $\bar{\tau}$ is a lump sum transfer received by the agent. Note that $\tau$, the income tax rate, applies to the financial income $r a(t)$ (provided that $a(t) \geq 0$ ). In each period, some agents die. Their wealth is redistributed to living agents in the form of a lump sum transfer; this is detailed below. Equation (6) describes the evolution of the agent's stock of

\footnotetext{
${ }^{9} \mathrm{We}$ assume that home production is in the budget constraint.

${ }^{10}$ People aged 60 or older may benefit from a universal old-age pension. This grant corresponds to $27 \%$ of the average formal net monthly wage.

${ }^{11} \mathrm{We}$ assume there are two competitive labor markets (formal and informal). The two wage rates $\left(w_{f}\right.$ and $\left.w_{i}\right)$ are competitive equilibrium prices.
} 
assets. Equation (7) defines the borrowing constraint, with $-\infty<\underline{a} \leq 0$ being the borrowing limit ${ }^{12}$.

The agent derives utility from consumption following a standard CRRA utility function. The flow of utility from future consumption is discounted at rate $\rho_{h}$. Following De Nardi et al. (2017), we assume that the discount rate depends on the health status. De Nardi et al. (2017) introduce a discount factor $\beta_{h}=1 /\left(1+\rho_{h}\right)$, lower for unhealthy individuals than for healthy ones. They show that such heterogeneity is necessary to reproduce the observed health-wealth gradient characterized by a lower asset accumulation by unhealthy individuals over their life-cycle. Our estimates confirm that, other things being equal, unhealthy individuals have a higher propensity to consume than healthy ones (See Section 2.5). This result supports the introduction of a higher discount rate $\rho_{h}$ (or lower discount factor $\beta_{h}$ ) for unhealthy individuals. The life-cycle expected utility can be written as ${ }^{13}$

$$
\mathbb{E}_{0}\left[\int_{0}^{\widetilde{T}} e^{-\rho_{h} t} u(c(t)) d t+e^{-\rho_{h} \widetilde{T}} \phi_{\varepsilon}(a(\widetilde{T}))\right]
$$

with

$$
u(c(t))=\frac{c(t)^{1-\sigma}-1}{1-\sigma}
$$

and

$$
\phi_{\varepsilon}(a)=\varepsilon \frac{(\kappa+a)^{1-\sigma}}{1-\sigma}
$$

with $\sigma \in] 0,1[\cup] 1, \infty[, \varepsilon>0$, and $\kappa>0$.

\footnotetext{
${ }^{12}$ It is worth noting that the borrowing constraint naturally implies that $a(t) \geq \underline{a}, \forall t$, which is not identical to equation (6). Suppose that in period $t$, the borrowing constraint is binding, that is, $a(t)=\underline{a}$. At time $t+d t$, we should have $a(t+d t) \geq \underline{a}$. A first-order expansion gives $a(t)+\dot{a}(t) d t=\underline{a}+\dot{a}(t) \geq \underline{a}$. Given that $\dot{a}(t)=y(z(t), t)+r \underline{a}+\bar{\tau}-c(t)$, we deduce that the borrowing constraint can be rewritten as $r \underline{a}+y(z(t), t)+\bar{\tau}-c(t) \geq 0$

${ }^{13} \mathrm{We}$ assume that health is not an input in the utility function because it has the same side effects than the health-dependent discount rate. In an alternative model we relax the assumption of the health-dependent discount rate and assume instead a utility function of the form $u(c, h)$ with $u(c, h)=\left(\xi_{h} c\right)^{1-\sigma} /(1-\sigma)$ and $\xi_{g}>\xi_{b}>0$. In this case $u_{c}(c, h)>0$, $u_{\xi_{h}}(c, h)>0$ and $u_{c, \xi_{h}}(c, h)<0$ which involves that the marginal utility of consumption of healthy individuals is lower than that of unhealthy individuals, all other things being equals. It results in a rise in consumption when an individual moves from good health to bad health. This is consistent with the higher propensity to consume of the unhealthy. These results are available upon request.
} 
The term $\phi_{\varepsilon}(a(\widetilde{T}))$ corresponds to the utility of the bequest made by an agent to his or her offspring. This technical assumption allows us to determine the optimal wealth of the agent at the end of his or her life (De Nardi (2004)). Without this terminal condition, the problem is not well-behaved.

It is also important to underline that $\widetilde{T}$ is the agent's random lifetime. We denote by $\nu\left(t, t^{\prime} ; h\right)$ the agent's health-dependent survival probability. It represents the probability that an agent of age $t$ reaches age $t^{\prime} \geq t$. Moreover, it satisfies $\nu(t, t ; h)=1$ and $\nu(t, T ; h)=0, T$ being the maximum time an agent can live $\mathrm{e}^{14} 15$.

We denote by $v(a(t), z(t), t)$ the value of an individual in state $(a(t), z(t))$ (with $z(t)=(j(t), h(t))$ ) and at age $t$. The goal of an individual agent is to maximize his or her life-cycle expected utility (8) subject to (6) and (7). The problem can be written recursively, and the agent's optimal decision rules solve the following Hamilton-Jacobi-Bellman equation:

$$
\begin{aligned}
& \rho_{h} v(a(t), z, t)=\max _{c(t), a(t)}\left\{u(c(t))+\partial_{a} v(a(t), z, t) \dot{a}(t)+\partial_{t} v(a(t), z, t)\right. \\
& +\sum_{z^{\prime} \in \mathcal{Z}, z^{\prime} \neq z} \lambda\left(z, z^{\prime}, t\right)\left[v\left(a(t), z^{\prime}, t\right)-v(a(t), z, t)\right] \\
& \left.-\partial_{2} \nu(t, t ; h)\left[\phi_{\varepsilon}(a(t))-v(a(t), z, t)\right]\right\} \\
& \quad-\dot{a}(t)+y(z, t)+(1-\tau \times 1\{a(t) \geq 0\}) r a(t)-c(t)+\bar{\tau}=0 \\
& \quad r \underline{a}+y(z, t)+\bar{\tau}-c(t) \geq 0
\end{aligned}
$$

The optimal consumption is given by the following optimality condition:

$$
\partial_{c} u(c(t))=\partial_{a} v(a(t), z, t)
$$

There is also a boundary condition ensuring that the borrowing constraint is satisfied:

$$
\partial_{a} v(\underline{a}, z, t) \geq \partial_{c} u(y(z, t)+r \underline{a}+\bar{\tau}) .
$$

\footnotetext{
${ }^{14}$ At $t$, the probability of being alive at $t+d t$ is given by $\nu(t, t+d t ; h) \simeq \nu(t, t ; h)+$ $\partial_{2} \nu(t, t ; h) d t=1+\partial_{2} \nu(t, t ; h) d t$. Likewise, the probability of being dead at $t+d t$ is $1-\nu(t, t+d t ; h) \simeq-\partial_{2} \nu(t, t ; h) d t$.

${ }^{15} \mathrm{We}$ assume that the survival function is

$$
\nu\left(t, t^{\prime} ; h\right)=\left[1-\frac{t^{\prime}-t}{T-t}\right]^{a_{h}}
$$

with $h=\{g, b\}$ and $a_{h}>0$.
} 
The HJB equation is solved backward, using the terminal condition:

$$
v(a(T), z, T)=\phi_{\varepsilon}(a(T))
$$

To solve the problem numerically, we assume that $\varepsilon$ is positive and very small. This terminal condition is necessary to solve the dynamic optimization problem. Otherwise, the optimal level of the agent's assets at the end of his life is undetermined. The policy rules solving the above problem take the following form:

$$
\begin{aligned}
& \dot{a}(t)=s(a(t), z, t) \\
& c(t)=c(a(t), z, t)
\end{aligned}
$$

\section{$3.2 \quad$ Firms}

As in Aiyagari (1994), we assume that wealth takes the form of productive capital. In addition, the stock of capital is only used by formal firms. This assumption is consistent with La Porta and Shleifer (2008, 2014), who show that informal firms are much less productive than formal ones. We assume that the informal sector and the formal sector produce the same good. The price of this good is normalized to 1 .

The firms operating in the formal sector produce $Y_{f}$ using a constantreturn-to-scale technology represented by a Cobb-Douglas production function

$$
Y_{f}=F\left(K, L_{f}\right)=K^{\alpha} L_{f}^{1-\alpha}
$$

where $K$ stands for capital, $L_{f}$ for formal employment, and $\left.\alpha \in\right] 0,1[$ is the share of capital. We assume that markets are perfectly competitive and that firms are price-takers. Firms choose the factor amounts that maximize their profits subject to technological constraints:

$$
\begin{aligned}
& \max _{K, L_{f}} \Pi_{f}=Y_{f}-w_{f} L_{f}-(r+\delta) K \\
& \text { s.t. } Y_{f}=K^{\alpha} L_{f}^{1-\alpha}
\end{aligned}
$$

The following optimality conditions must hold:

$$
\begin{aligned}
& \frac{\partial F\left(K, L_{f}\right)}{\partial K}=\alpha\left(\frac{K}{L_{f}}\right)^{\alpha-1}=r+\delta \\
& \frac{\partial F\left(K, L_{f}\right)}{\partial L_{f}}=(1-\alpha)\left(\frac{K}{L_{f}}\right)^{\alpha}=w_{f}
\end{aligned}
$$


Firms operating in the informal sector use labor as their only input for the production process. Output is given by the following linear (constantreturn-to-scale) production function:

$$
Y_{i}=Z\left(L_{i}\right)=\bar{Z} L_{i}
$$

where $\bar{Z}$ is a scaling parameter. These firms also choose the factor amounts that maximize their profits:

$$
\begin{aligned}
& \max _{L_{i}} \Pi_{i}=Y_{i}-w_{i} L_{i} \\
& \text { s.t. } Y_{i}=\bar{Z} L_{i}
\end{aligned}
$$

Entry is free, so that profits are zero. One has

$$
\bar{Z}=w_{i}
$$

If we denote by $C$ the aggregate flow of consumption, we have the following equilibrium condition in the good's market:

$$
C+\delta K=Y_{f}+Y_{i}+b L_{u}
$$

where $\delta$ is the depreciation rate of capital and $L_{u}$ is the non-employment pool.

\subsection{Stationary distribution}

Equations (12) and (13) are the optimal decision rules of an agent in state $(a, z)$ and of age $t \in[0, T]$. Let us denote by $g(a, z, t)$ the stationary joint density of $a, z$, and $t$. The density function satisfies the following Kolmogorov equation:

$$
\begin{aligned}
0 & =-\partial_{t} g(a, z, t)-\partial_{a}(s(a, z, t) g(a, z, t))-\lambda(z, z, t) g(a, z, t) \\
& +\sum_{z^{\prime} \in \mathcal{Z}, z^{\prime} \neq z} \lambda\left(z^{\prime}, z, t\right) g\left(a, z^{\prime}, t\right)+\partial_{2} \nu(t, t ; h) g(a, z, t)
\end{aligned}
$$

Starting from the given initial condition $g(a, z, 0)$ and using the Kolmogorov equation (21), the density is computed for $t \in] 0, T]$ through a forward iteration.

The density function $g$ satisfies:

$$
\sum_{z \in \mathcal{Z}} \int_{\underline{a}}^{\infty} \int_{0}^{T} g(a, z, t) d t d a=1
$$

The following conditions must hold: 


\section{Aggregate capital and consumption}

$$
\begin{aligned}
& K=\sum_{z \in \mathcal{Z}} \int_{\underline{a}}^{\infty} \int_{0}^{T} a g(a, z, t) d t d a \\
& C=\sum_{z \in \mathcal{Z}} \int_{\underline{a}}^{\infty} \int_{0}^{T} c(a, z, t) g(a, z, t) d t d a
\end{aligned}
$$

\section{Labor market equilibrium}

$$
\begin{aligned}
L_{j} & =\sum_{h=g, b} \int_{\underline{a}}^{\infty} \int_{0}^{t^{\star}} g(a,(j, h), t) \ell((j, h), t) d t d a \quad j=f, i \\
L_{u} & =\sum_{h=g, b} \int_{\underline{a}}^{\infty} \int_{0}^{t^{\star}} g(a,(u, h), t) d t d a
\end{aligned}
$$

Determination of the lump sum transfer We assume that accidental bequests are redistributed equally across all individuals. We also assume that the government surplus $\Pi$ is redistributed in a similar manner. This surplus corresponds to the sum of taxes collected on all incomes minus the retirement pensions. Formally, the government surplus $\Pi$ and the lump sum transfer $\bar{\tau}$ are given by

$$
\begin{aligned}
\Pi= & \tau\left(r \sum_{z \in \mathcal{Z}} \int_{\underline{a}}^{\infty} \int_{0}^{T} a g(a, z, t) d t d a+w_{f} \sum_{h=g, b} \int_{\underline{a}}^{\infty} \int_{0}^{t^{\star}} \ell((f, h), t) g(a,(f, h), t) d t d a\right) \\
& -\bar{p} \sum_{h=g, b} \int_{\underline{a}}^{\infty} \int_{t^{\star}}^{T} g(a,(d, h), t) d t d a \\
\bar{\tau}= & -\sum_{z \in \mathcal{Z}} \int_{\underline{a}}^{\infty} \int_{0}^{T} a g(a, z, t) \partial_{2} \nu(t, t ; h) d t d a+\Pi
\end{aligned}
$$

\section{Numerical analysis}

How well does the model capture salient features of the data? What would be the wealth of an individual in the absence of health risks? What is the impact of a health shock on wealth and consumption? In this impact, what is the relative contribution of the change in income, consumption, transition probabilities, and life expectancy? To answer these questions, we estimate the model and perform various numerical simulations. 


\subsection{Calibration and estimation strategy}

We first set the value of some parameters based on external sources. We then use a minimization routine to estimate the remaining parameters so that the model matches several empirical characteristics of the life-cycle wealth distribution.

\subsubsection{Parameter set externally.}

We consider a life-cycle period of 75 years, from 15 to 90 years old. Every individual aged 15 entering the labor market is assumed to be non-employed and in good health. We consider annual frequencies. Following the standard practice, we impose the constraint that the risk aversion coefficient be equal to $\sigma=2$. Using the Penn World Tables, we set the depreciation rate of capital to $\delta=0.05$. As it is considered standard, we set the share of capital in the production function to $\alpha=1 / 3$.

The average income tax rate $^{16}$ we obtain from the NIDS data is $20.67 \%$. The public retirement pension calculated from NIDS amounts to $27 \%$ of the average net wage in the formal sector. We then assume that:

$$
\bar{p}=\rho_{p} w_{f}(1-\tau) \frac{\sum_{h=g, b} \int_{\underline{a}}^{\infty} \int_{0}^{t^{\star}} \ell(f, h, t) g(a,(f, h), t) d t d a}{\sum_{h=g, b} \int_{\underline{a}}^{\infty} \int_{0}^{t^{\star}} g(a,(f, h), t) d t d a}
$$

where $\rho_{p}$ is the replacement rate, equal to $27 \%$, and the last term defines the average net formal wage. The borrowing limit is set to zero $(\underline{a}=0)$.

We use the estimated transition matrix by age group obtained in Section 2.2 to set $\lambda_{z, z^{\prime}, t}$ and the estimated survival probabilities to set $\nu\left(t, t^{\prime} ; h\right)$ (reported in Appendix A).

\footnotetext{
${ }^{16}$ Income tax in South Africa is progressive and increases in steps as the income increases. To maintain a tractable framework, we consider an identical tax rate calculated according to the actual progressive tax schedule by averaging the income taxes paid by individuals.
} 
Table 2: Calibrated parameters.

\begin{tabular}{lcc}
\hline Calibrated parameters & Symbol & Value \\
\hline Risk aversion coefficient & $\sigma$ & 2 \\
Depreciation rate of capital & $\delta$ & 0.05 \\
Share of capital & $\alpha$ & $1 / 3$ \\
Average income tax rate & $\tau$ & $20.67 \%$ \\
Replacement rate & $\rho_{p}$ & $27 \%$ \\
Borrowing constraint & $\underline{a}$ & 0 \\
Asset support & {$[\underline{a}, \bar{a}]$} & {$[0,20]$} \\
\hline Life-cycle specification & Symbol & Value \\
\hline Starting age & $t_{0}$ & 15 \\
Final age & $T$ & 90 \\
Age step & $d t$ & 1 \\
Retirement age & $t^{\star}$ & 60 \\
Initial status & $\{j, h\}$ & $\{u, g\}$ \\
\hline
\end{tabular}

\subsubsection{Parameters set internally}

The remaining parameters are estimated. Our goal is to reproduce (i) the life-cycle wealth changes and (ii) the life-cycle wage changes. To assess the model's performance in matching the empirical moments, we divide the life cycle into age groups. Indeed, it is challenging to compute the life-cycle series from the data without having erratic movements due to the limited number of individuals at some age groups ${ }^{17}$. For this reason, we consider age groups defined as consecutive five-year periods, except for the first one: $(15-24,25-29,30-34, \ldots)$. In other words, there are a total of nine age groups. Although the model is simulated over a long horizon (up to age 90), for the estimation, we only focus on the period of interest that is related to activity, that is, ages 20 through 60 .

- For (i), we focus on the wealth change with respect to its initial value, by job status (formal, informal, and non-employed) and health status (good and bad). For each series, we investigate the wealth evolution by quartile (Q1, Q2, Q3). In total, we have $(3+2) \times 3=15$ life-cycle series related to wealth.

- For (ii), since there is no heterogeneity in wages for workers of the same age in the model, we focus on the life-cycle profile of the average wage

\footnotetext{
${ }^{17}$ All the investigated series are built using the five waves of the NIDS over the period 2008-2017.
} 
in the formal and informal sectors by health status. We then have four life-cycle series related to wages.

As there are nine age groups, we have $N=(15+4) \times 9=171$ moments. The set of observations at each age is denoted by $\left\{\boldsymbol{Y}_{1, t}, \boldsymbol{Y}_{2, t}, \ldots, \boldsymbol{Y}_{N, t}\right\}_{t=t_{0}}^{t^{\star}}$. The set of structural parameters is

$$
\Theta=\left\{\bar{Z}, b, \rho_{g}, \rho_{b}, \eta_{0}^{f g}, \eta_{0}^{f b}, \eta_{1}^{f g}, \eta_{1}^{f b}, \eta_{0}^{i g}, \eta_{0}^{i b}, \eta_{1}^{i g}, \eta_{1}^{i b}\right\}
$$

The strategy is to find the values of the parameters that best fit the lifecycle series observed in the data ${ }^{18}$. Formally, the optimization problem is expressed as

$$
\hat{\Theta}=\underset{\Theta}{\arg \min } \sum_{t=0}^{t^{\star}} \sum_{i=1}^{N}\left(\boldsymbol{Y}_{i, t}^{d}-\boldsymbol{Y}_{i, t}^{m}(\Theta)\right)^{2}
$$

where $\boldsymbol{Y}_{i, t}^{m}(\Theta)$ are the simulated life-cycle series. We use an adaptive grid to solve problem (22). The process consists of constructing a wide, multidimensional grid covering the space of the parameter values and refining the grid at each iteration around the values most likely to match the target ${ }^{19}$.

Table 3 shows the parameter values obtained from the estimation procedure. The value of the TFP parameter $\bar{Z}$ for the informal sector is approximately one-third of that for the formal sector (which is implicitly equal to 1 ). This result is not surprising given that informal firms tend to be less productive and pay lower wages. Home production $b$ is equal to 0.52 , approximately one-third of the average informal wage rate. The discount rate differential for healthy and unhealthy individuals is significant: 0.05 for the former and 0.17 for the latter. This difference is consistent with De Nardi et al. (2017), who find a difference in the discount factor $(1+\rho)^{-1}$ of approximately 0.1 . When combined with the wage rate $w_{j}$, the parameters governing the labor efficiency $\left(\eta_{0}^{z}\right.$ and $\left.\eta_{1}^{z}\right)$ imply a slower increase in the wages of unhealthy individuals across the life cycle and a lower initial wage for informal workers than for formal workers.

\footnotetext{
${ }^{18}$ The mapping between the observed series and the simulated ones is not straightforward as the asset levels computed from the data cannot directly be compared to those obtained directly from the data. The same is true for wages. We then focus on the variation over the life cycle, that is, the deviation of wealth and wages with respect to their initial values at age $t_{0}$. We express the deviations of wealth and wages as a fraction of the average annual net formal wage so as to compare the model and the data.

${ }^{19}$ See Albertini and Terriau (2019a) for a detailed description of the algorithm.
} 
Table 3: Estimated parameters

\begin{tabular}{lcc}
\hline Parameter & Symbol & Value \\
\hline Scaling output, informal & $\bar{Z}$ & 0.37 \\
Home production & $b$ & 0.52 \\
Discount rate, good & $\rho_{g}$ & 0.05 \\
Discount rate, bad & $\rho_{b}$ & 0.17 \\
Scale wage efficiency, formal, good & $\eta_{0}^{f g}$ & 0.96 \\
Scale wage efficiency, formal, bad & $\eta_{0}^{f b}$ & 0.25 \\
Curvature wage efficiency, formal, good & $\eta_{1}^{f g}$ & 0.38 \\
Curvature wage efficiency, formal, bad & $\eta_{1}^{f b}$ & 0.70 \\
Scale wage efficiency, informal, good & $\eta_{0}^{i g}$ & 1.1 \\
Scale wage efficiency, informal, bad & $\eta_{0}^{i b}$ & 1.1 \\
Curvature wage efficiency, informal, good & $\eta_{1}^{i g}$ & 0.55 \\
Curvature wage efficiency, informal, bad & $\eta_{1}^{i b}$ & 0.51 \\
\hline
\end{tabular}

\subsection{Estimation results}

We first take a look at the model's fit at the aggregate level. Table 4 displays the standard moments often used for assessing a model's performance in reproducing consistent inequalities observed in the data. The simulated aggregate distribution, summarized by the percentage of wealth owned by the top $1 \%, 5 \%, 10 \%$, and so on, of the population, is broadly consistent with its empirical counterpart. As shown by Figure 2, the model slightly underestimates the wealth of the top $1 \%$ and $5 \%$ of individuals and overestimates the fraction of poor households. However, the model matches the Gini coefficient found in the data very closely ${ }^{20}$.

Table 4: Moments

\begin{tabular}{lccccccc}
\hline & \multirow{2}{*}{ GINI } & \multirow{2}{*}{ K/Y } & \multicolumn{6}{c}{ Percentage wealth in the top } \\
\cline { 4 - 8 } & & & $\mathbf{1 \%}$ & $\mathbf{5 \%}$ & $\mathbf{1 0 \%}$ & $\mathbf{2 0 \%}$ & $\mathbf{5 0 \%}$ \\
\hline Model & 0.69 & 2.2 & 6.62 & 26.56 & 44.62 & 68.88 & 97.73 \\
Data & 0.70 & 2.9 & 12.10 & 39.04 & 56.49 & 74.12 & 93.98 \\
\hline
\end{tabular}

\footnotetext{
${ }^{20}$ As is usually done, we remove from the data the top $1 \%$, as well as the bottom $1 \%$. Consequently, the Gini computed from the data appears lower than the one reported in some international comparisons (which exceeds 0.80).
} 
Figure 2: Lorentz curve

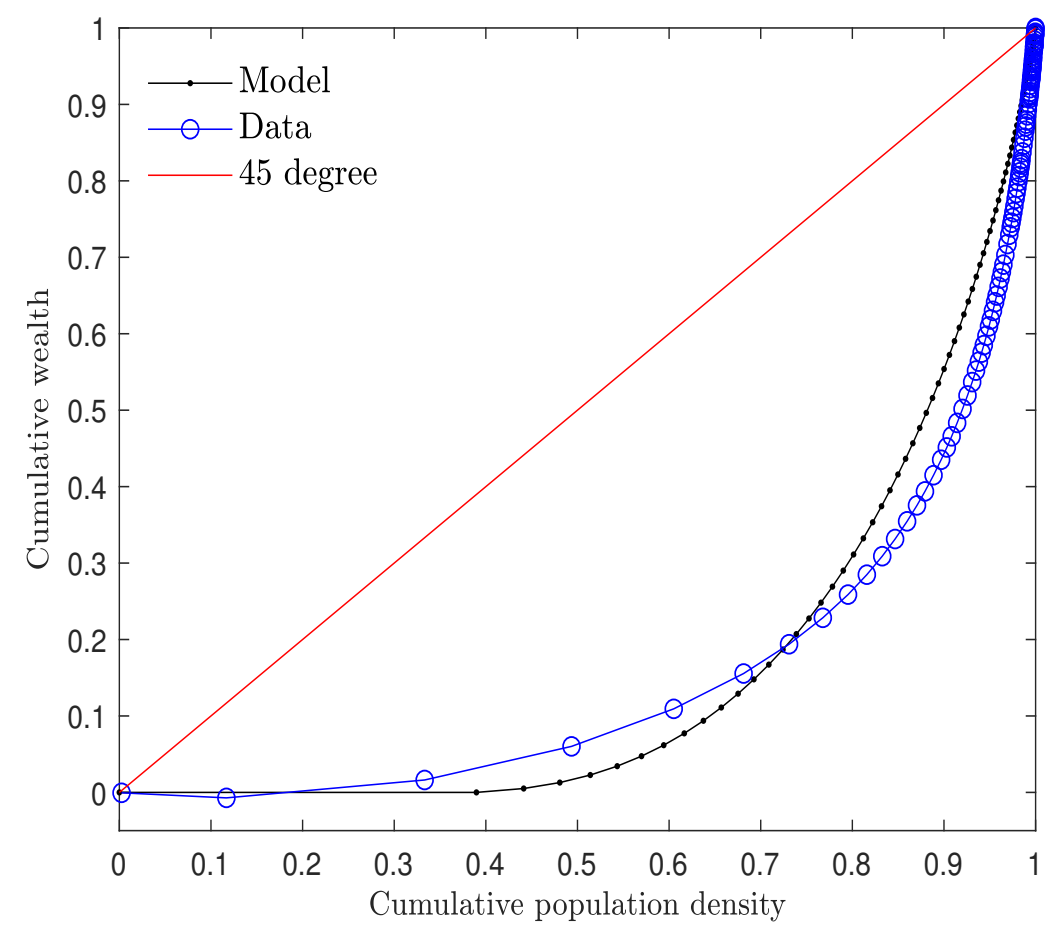

Figure 3 shows the simulated life-cycle profile of wealth by job status. Wealth increases with age in all job categories. Not surprisingly, the increase in wealth is stronger for formal workers than for informal workers. Indeed, median wealth increases by approximately 200,000 rands (or USD 13,538) between age 20 and 60 , a rise $42 \%$ larger than that for informal workers and $230 \%$ larger than that of non-employed workers. Heterogeneities in asset accumulation across job status are even higher for individuals in the $3^{\text {rd }}$ quartile of their job status. In the data, the wealth of non-employed workers barely changes before age 40. All these characteristics are captured well by the model, which produces consistent wealth changes. It slightly overestimates the increase in the wealth of non-employed workers but closely matches heterogeneities across job status and the life cycle. 
Figure 3: Wealth across the life cycle, by job status
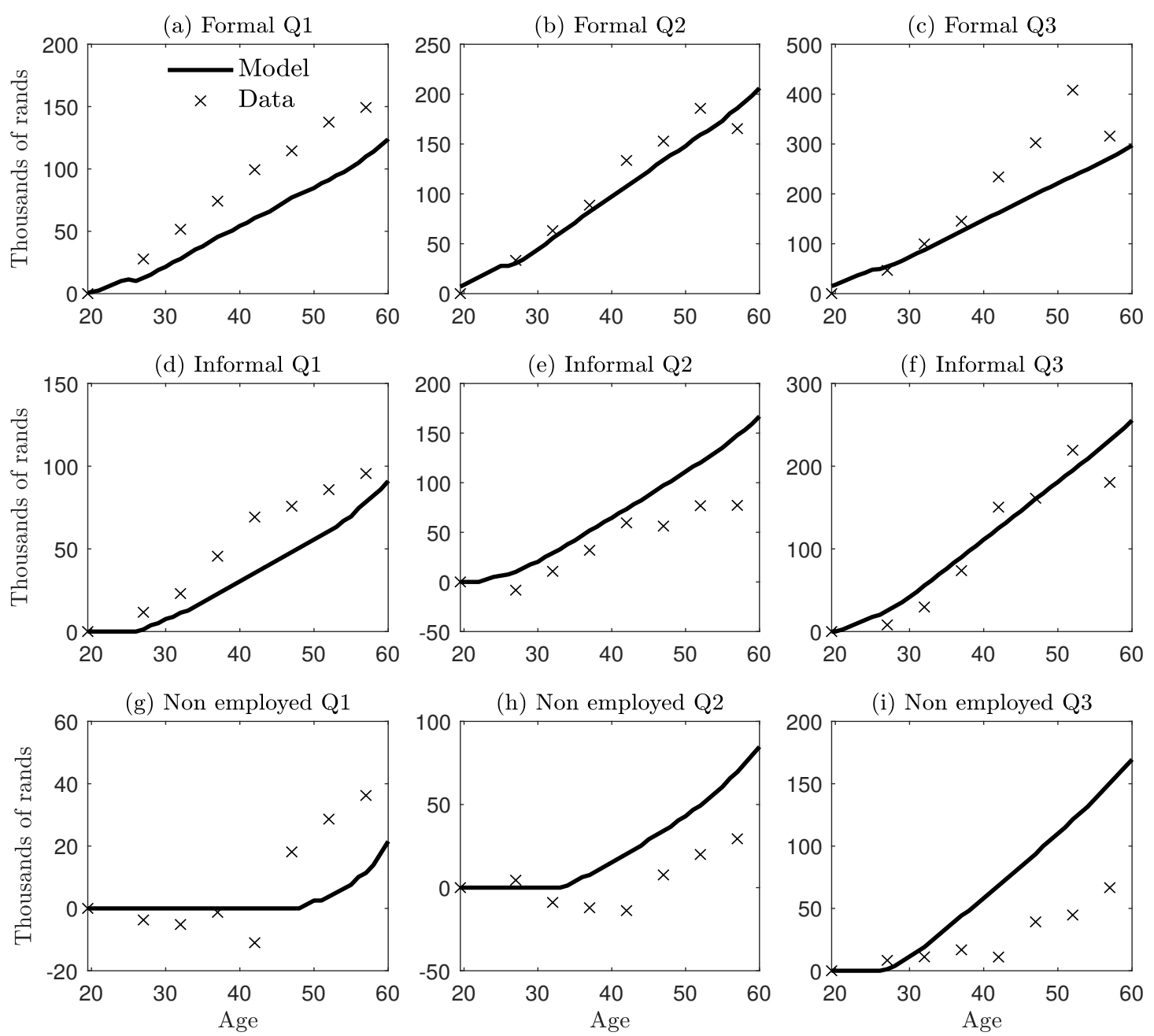

Notes: Deviation of wealth with respect to wealth at age $t_{0}$. Converted in rand from the model using the average net formal wage. Q1, Q2, and Q3 are quartiles, representing the wealth limit between the bottom $25 \%$ /top $75 \%$, bottom $50 \% /$ top $50 \%$ and bottom $75 \% /$ top $25 \%$, respectively.

We now investigate the health-wealth gradient. Figure 4 displays the life-cycle profile of wealth by health status. Consistent with the literature, where a similar quantitative evaluation is applied but in other countries, wealth accumulation is lower for individuals in poor health. This is the case in South Africa, whatever an individual's wealth quartile may be. The difference in asset accumulation is increasing over the life cycle. However, 
the model has some difficulty in matching the observed gap between the two groups despite a higher discount rate for unhealthy individuals $\left(\rho_{b}=0.17\right.$ vs $\left.\rho_{g}=0.05\right)$. Increasing the difference in the discount rate between healthy and unhealthy individuals results in a better match with the health-wealth gradient but reduces the ability of the model to match the heterogeneous wealth trajectories across job status.

Figure 4: Wealth across the life cycle, by health status

(a) Q1

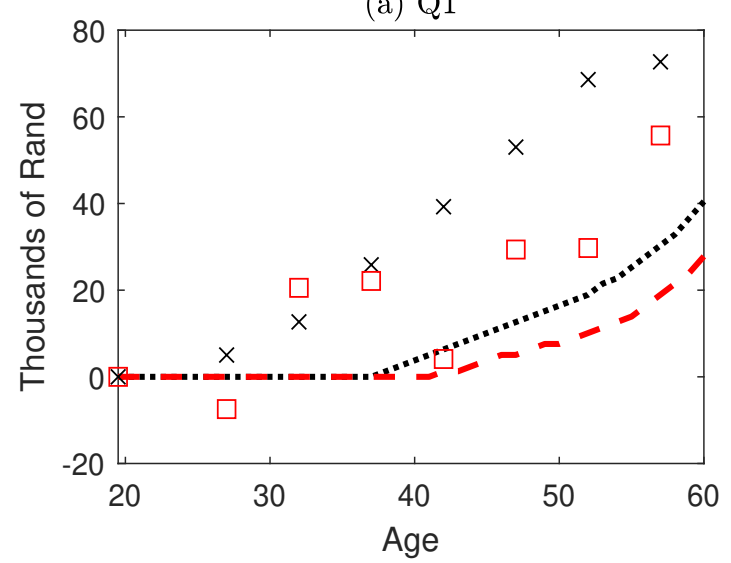

(c) Q3

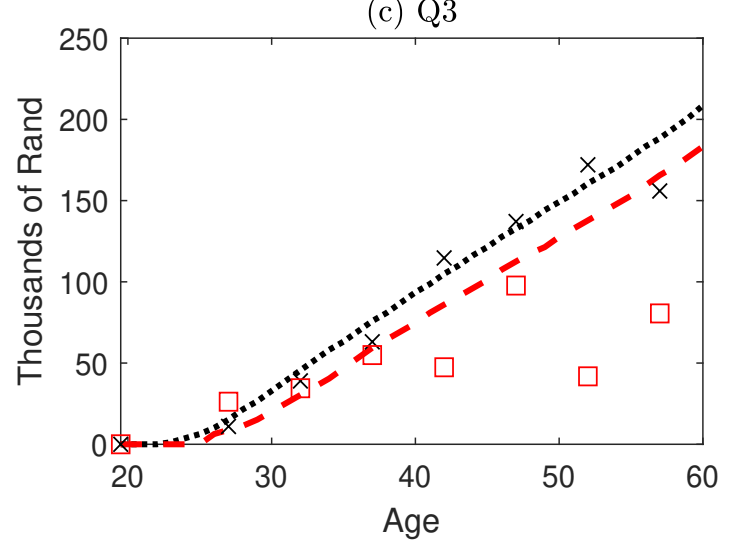

(b) Q2

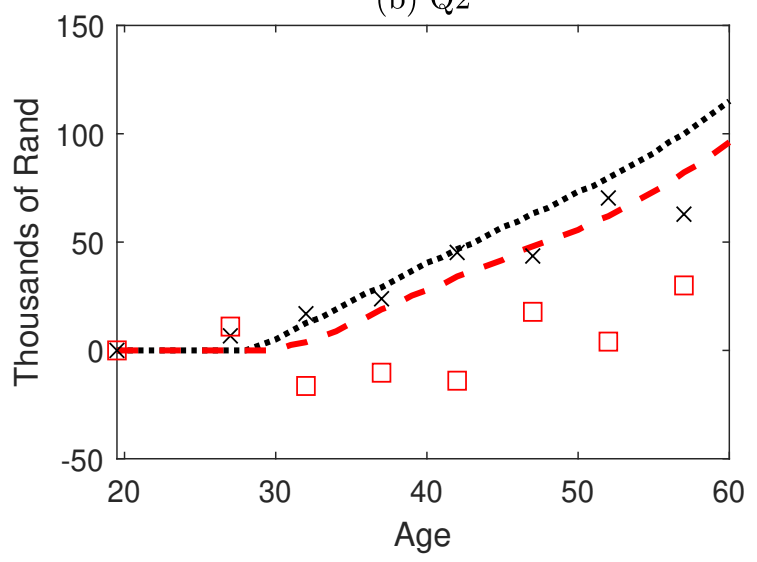

.........Good health model

- - Bad health model

$\times$ Good health data

$\square \quad$ Bad health data

Note: Deviations of wealth with respect to wealth at age $t_{0}$. Converted in rand from the model using the average net formal wage. Q1, Q2, and Q3 are quartiles, representing the wealth limit between the bottom 25\%/top 75\%, bottom 50\%/top $50 \%$ and bottom $75 \% /$ top $25 \%$, respectively.

Finally, Figure 5 shows the life-cycle profile of wages. Because of the labor efficiency functions, the model has no difficulty in replicating the wage trends. Wages are increasing and concave with age, the typical wage profile found in 
other countries. Average wages quadruple in the formal sector between ages 15 and 60. In the informal sector, average wages are almost twice as low as those in the formal sector. Nevertheless, we observe a strong increase over the life cycle. In both sectors, the wages of unhealthy individuals are shown to be significantly lower than those of healthy ones.

Figure 5: Wages

(a) Formal - good health

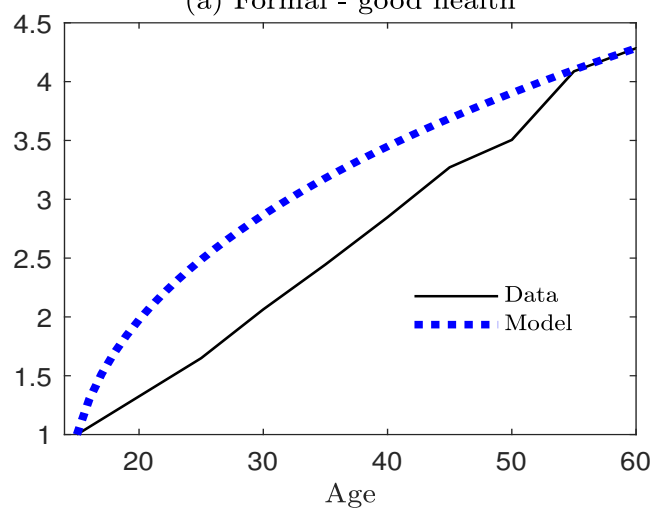

(c) Informal - good health

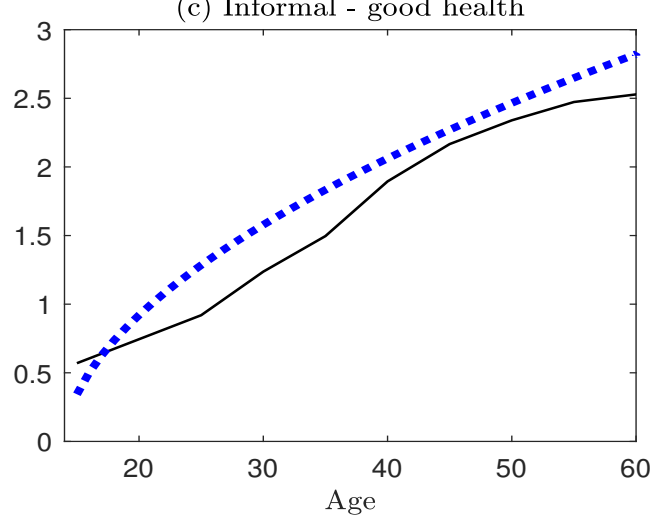

(b) Formal - bad health

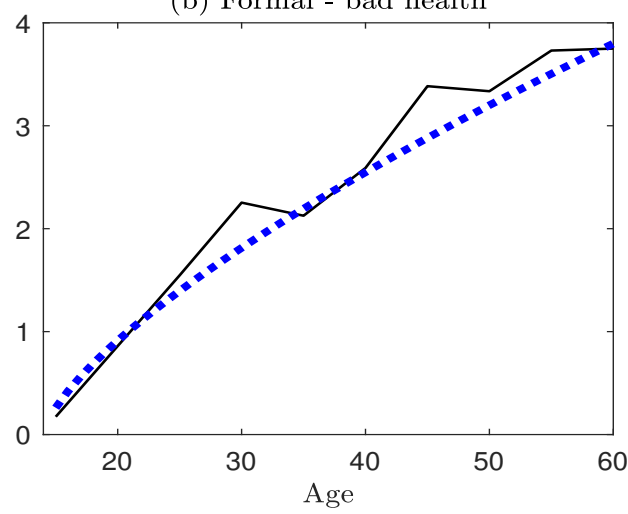

(d) Informal - bad health

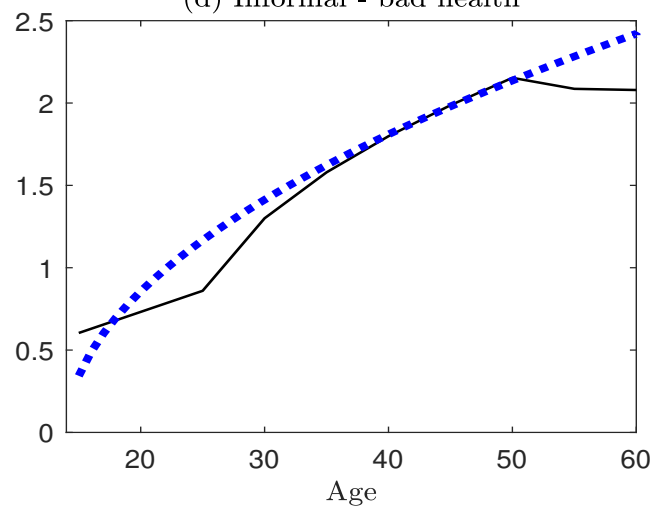

Note: Wages are expressed as a function of the average net wage in the formal sector at age $t_{0}$.

\subsection{Counterfactual analysis}

How costly is bad health over the life cycle? What transmission channels are more important in explaining the impact of a health shock on wealth? Using the model, we perform several simulation exercises to quantify the wealth and consumption gains from removing the health risks. Throughout 
the simulations, we distinguish among four channels that govern the impact of health risks. In the alternative scenarios, we consider only one of these channels to be at play, to quantify its contribution. The four channels are:

- The income channel corresponds to the decline in income resulting from the lower labor efficiency of unhealthy employed workers. Income falls when the individual becomes unhealthy: $\ell(j, g) \longrightarrow \ell(j, b)$. To "mute" this channel, we assume that individuals have the same income, that is $y((j, b), t)=y((j, g), t)$.

- The consumption channel involves a rise in consumption due to the higher discount rate of unhealthy individuals. When a bad health shock occurs, individuals tend to consume more, which lowers savings and asset accumulation. To "mute" this channel, we assume that individuals have the same policy rules for consumption $c(t)$, that is, $c(a(t),(j, b), t)=c(a(t),(j, g), t)$.

- The probability channel is related to the change in transition probabilities of moving from one job status to another. Being in bad health at age $t$ affects the probabilities of switching job status at age $t+1$. As shown by Figure 1, unhealthy employed workers are more likely to become non-employed and non-employed ones are less likely to find a job. Workers then may have a different labor market trajectory due to this change in transition probabilities. To "mute" this channel, we assume that for each job status, unhealthy individuals face the same probabilities as healthy ones, that is, $\lambda\left((j, b), z^{\prime}, t\right)=\lambda\left((j, g), z^{\prime}, t\right)$.

- The survival channel corresponds to the lower survival probability of unhealthy individuals compared to that of healthy ones. As before, to "mute" this channel, we simply assume that the survival rate is the same, regardless of health status, that is: $\nu\left(t, t^{\prime} ; b\right)=\nu\left(t, t^{\prime} ; g\right)$

\subsubsection{Aggregate impact of health risk}

We first ask what the path of wealth and consumption over the life cycle would have been if the probability of being in bad health was zero, other things being equal ${ }^{21}$. We simulate 10000 individual trajectories with and without the health risk and compute the differences between the trajectories. We then average the differences. In the absence of health risks, individuals

\footnotetext{
${ }^{21}$ Throughout the simulation exercises, we assume that the interest rate, wages, and transfers are the same as those in the benchmark. Consequently, we focus on the micro effects and not on the general equilibrium effects.
} 
are always in good health but still face income risks and move from one job status to another.

Figure 6 depicts the gains from removing the health risks as a function of an individual's age and his or her initial wealth quartile. The total wealth gains (black solid line) are zero up to age 25 as the probability of being in bad health is zero before that. Thereafter, the gains increase rapidly and may reach $40 \%$ of the average annual net formal wage at age 60, depending on which wealth quartile the individual belongs to. The largest wealth and consumption differentials are concentrated in rich households. Poorest individuals simply have few assets and many of them already have reached their borrowing limit. Consequently, health risks have a higher impact on individuals with more to lose and a limited effect on individuals at the borrowing constraint $^{22}$.

The major driver of wealth gains is the probability channel, especially for individuals in the first and second quartiles. As shown by Figure 3, poor individuals are more likely to be non-employed than rich ones. In addition, there is a clear difference between healthy and unhealthy individuals in the probability that an unemployed individual finds a job (Figure 1). By increasing non-employment spells, health risks trap poor individuals in a vicious cycle where job access markedly decreases, followed by a strong decline in wealth and consumption.

The income channel plays a significant role, especially for individuals in the fourth quartile. The reason is that the proportion of formal workers is higher in this wealth category, implying a larger income loss from bad health than in other job categories. The consumption channel has a minor impact. Healthy individuals have a lower discount rate, which curbs their propensity to consume and raises their asset accumulation.

Early in the life cycle, the contribution of the survival channel is low as the survival rate gap between healthy and unhealthy individuals is small. Above age 50, it plays a more significant role in the evolution of wealth and accounts for half of the increase in consumption. The larger contribution of the survival channel comes from a composition effect in the population. Individuals that benefit from an increase in life expectancy tend to be older and more often unhealthy. Given that individuals save less and consume more when they are older, the rise in life expectancy propagates more into consumption than into saving.

\footnotetext{
${ }^{22}$ Note that the results could be different if we expressed the wealth gains as a percentage deviation from the benchmark wealth. However, as many individuals experienced zero wealth at the benchmark during their life cycle, the gains could be infinite. It thus seems more convenient to express the differences as a function of an aggregate price in the economy. Therefore, we chose the average net formal wage.
} 
Figure 6: Aggregate impact of health risks

(a) Wealth Q1

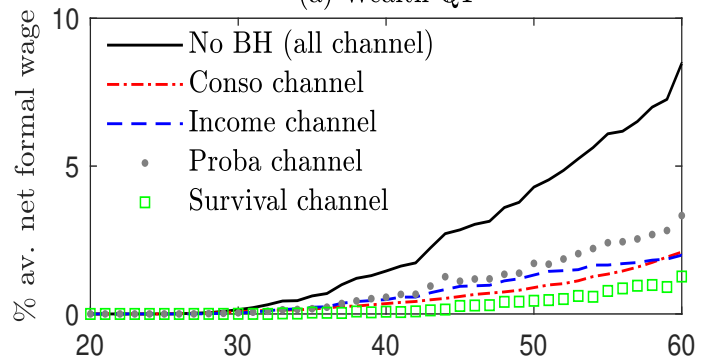

(c) Wealth Q2

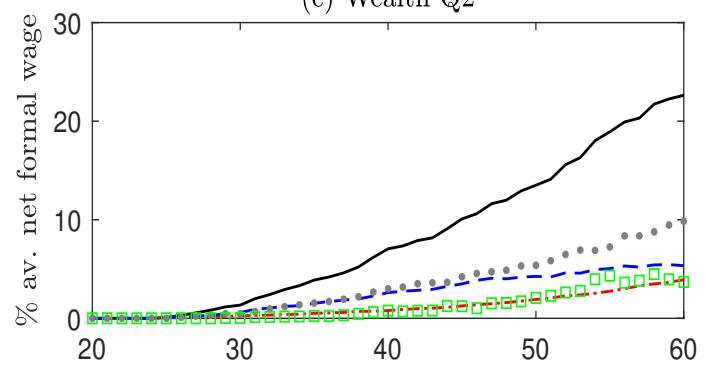

(e) Wealth Q3

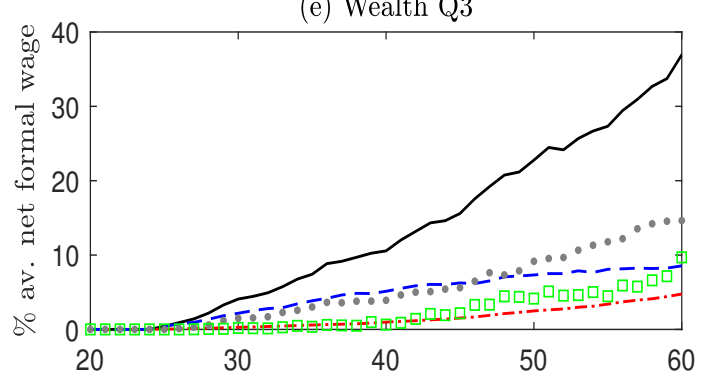

(e) Wealth Q4

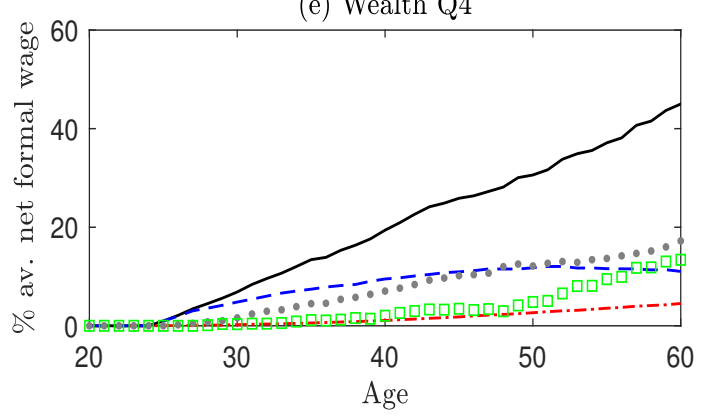

(b) Consumption Q1

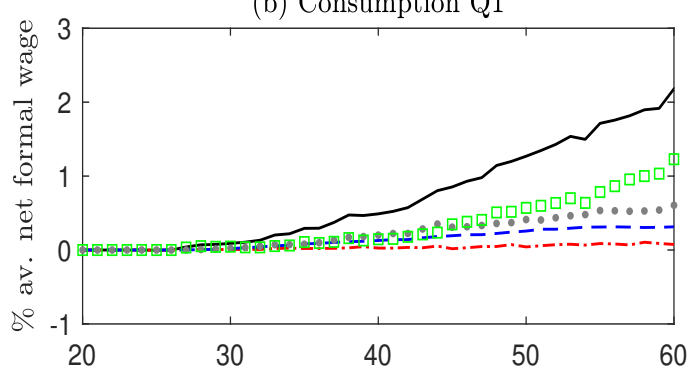

(d) Consumption Q2

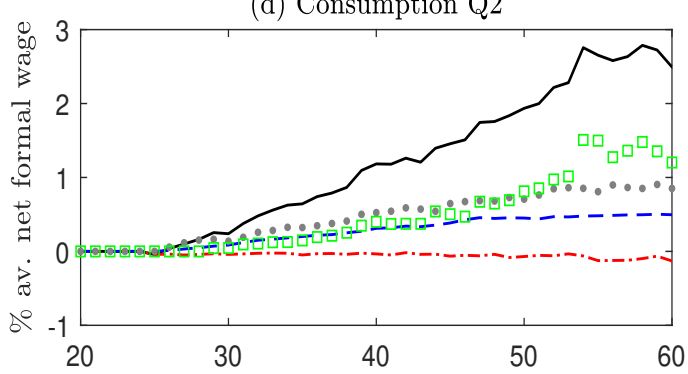

(f) Consumption Q3

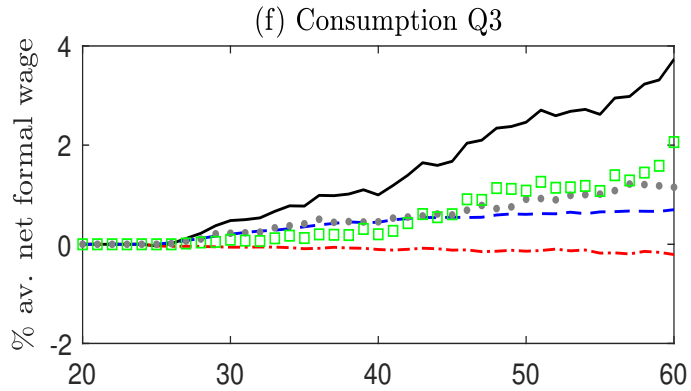

(h) Consumption Q4

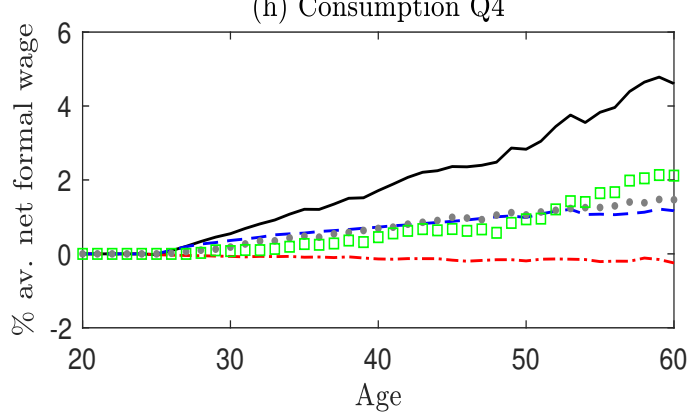

Note: Wealth and consumption gains correspond to the difference between the alternative scenario (no health risks) and the benchmark case. This difference is expressed as a percentage of the average net formal wage. The latter is computed using all the individuals in the formal sector and across age, weighted by the number of formal workers at each age. The gains are averaged over the number of individuals in each quartile $Q_{i}, i=1, \ldots, 4$. 


\subsubsection{Propagation effects of heath shocks}

We now investigate the "recovery" effects of a health shock. Our question is how wealth and consumption evolve following a one-period bad health shock. To illustrate how long the health shock persists over the life cycle, we compute impulse response functions (Figure 7). They show the evolution of a variable when the individual is unhealthy during only one period minus the evolution of the same variable when the individual is always healthy. We simulate 10,000 individual trajectories and average the differences between the two scenarios across individuals for every period following the shock. For comparison purposes, we analyze how important the initial job status is when the bad health shock occurs and disentangle the relevant channels that explain the results in each case $^{23}$.

The health shock may have a strong impact on saving and consumption, but the size of the effect crucially depends on the job status. Indeed, the decrease in wealth as a percentage of the average net formal wage amounts to more than $30 \%$ for formal workers (panel (a)). The decline is approximately $12 \%$ for informal workers and $4 \%$ for the non-employed (panels (c) and (e), respectively). These differences are explained well by the income channel. Unhealthy formal workers undergo a sharp decline in income, which translates into a decrease in saving and consumption. In addition, formal workers being the wealthiest individuals, the deviation of the variables is stronger. Indeed, individuals at - or close to - the borrowing limit will not experience a significant change in their wealth.

Although the impact of the shock is larger for formal workers than for informal workers or non-employed ones, the opposite is true for the persistence effects of the shock. For instance, for formal workers, it takes 12 years to compensate for half of the impact of the shock. This duration is approximately 20 years for informal workers and above 30 years for the non-employed. These differences come from the channel through which the shock propagates. For informal workers and the non-employed, the probability channel represents the major driver of how the variables change. It shapes approximately half the change in the consumption and wealth of informal workers and almost all the change for the non-employed. The health shock significantly increases the informal workers' exit rate to non-employment and reduces the probability of finding a job for the non-employed. As a consequence, jobless spells last longer, which reduces the speed of the "recovery" of wealth and consumption. Once again, these results illustrate the poverty trap, where individuals are more likely to be unhealthy and less likely to escape non-employment.

\footnotetext{
${ }^{23}$ Given that the bad health shock occurs during a single period, the survival channel does not matter in this exercise. We thus focus on the other channels.
} 
The consumption effect, stemming from the change in the discount rate, plays an important role on impact but has a marginal effect in the subsequent periods. Consumption rises by approximately $1 \%$ for informal workers and the non-employed but barely changed for formal workers.

Figure 7: Impulse response functions
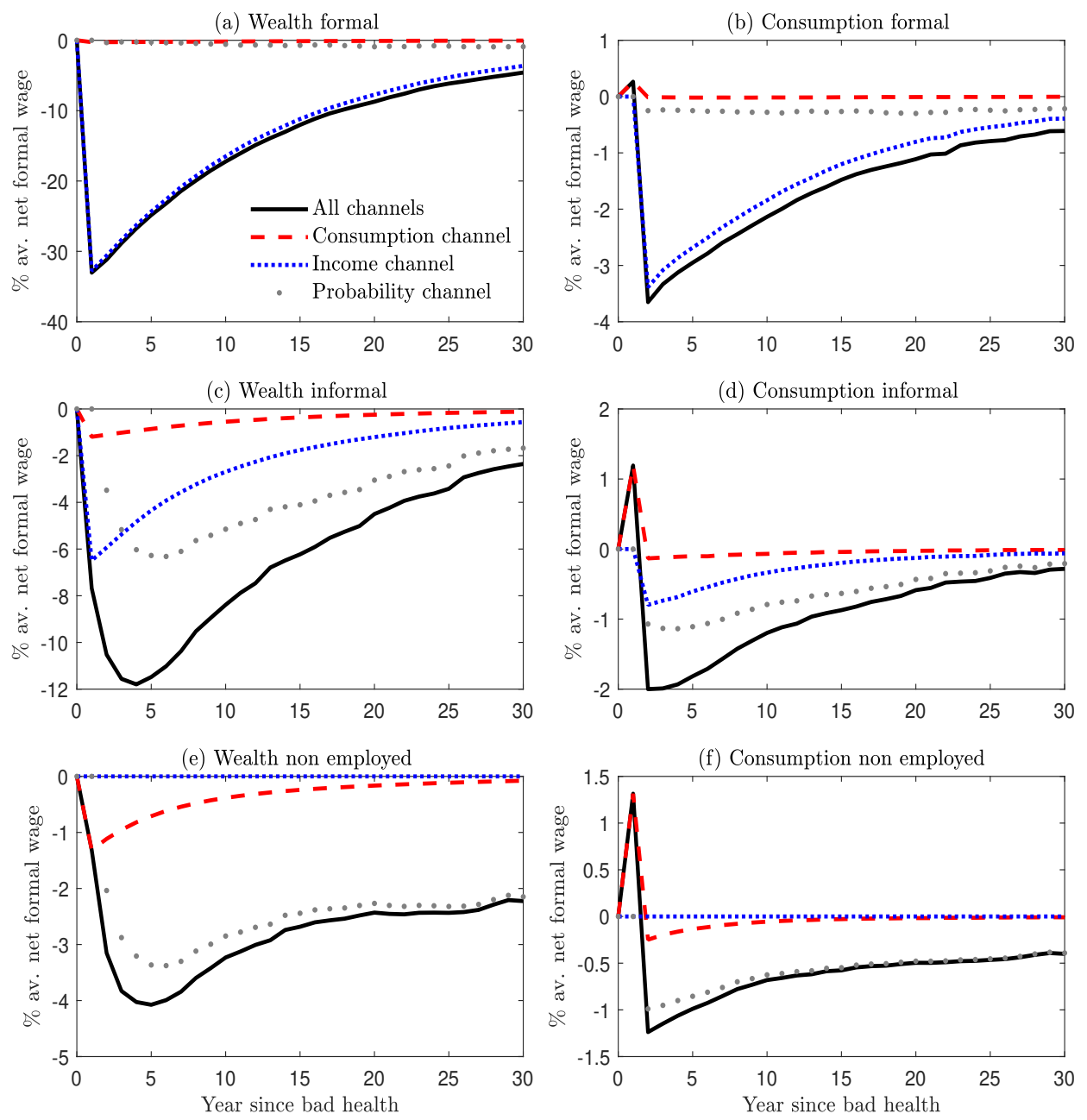

Note: Generalized impulse response functions to a one-period health shock occurring at age 30. The functions are computed by averaging, for each year, the wealth and consumption differentials (one year unhealthy vs always healthy) of 10,000 individual trajectories. The bad health shock is assumed to occur when the individual is in a formal job (panels (a) and (b)), in an informal job (panels (c) and (d)), or non-employed (panels (d) and (e)). 


\section{Conclusion}

In this study, we quantify the wealth impact of health risks over the life cycle in South Africa. Using individual data, we estimate the transition probabilities between job and health statuses. We show that unhealthy individuals are less likely to access formal jobs and have a higher probability of moving to (or remaining in) non-employment. Moreover, workers with informal jobs, which are often characterized by poor working conditions, are more likely to become unhealthy compared to formal workers. This results in a poverty trap, in which some individuals face recurring spells of non-employment and informal employment.

We use a heterogeneous agent model with uninsured idiosyncratic income and health risks to quantify the impact of bad health on wealth and consumption. Using state-of-the-art continuous-time solution techniques, we solve and estimate a model with South African data. Although simple and fairly tractable, the model produces consistent life-cycle series of wealth and the inequalities observed in the data. Using counterfactual scenarios, we quantify the impact of health risks on wealth accumulation and consumption. We then perform numerical simulations to examine the respective contribution of the different channels outlined in the model in shaping the life-cycle profile of wealth and consumption.

Our results stress the need to reduce informal employment and nonemployment, to lift people out of the poverty and poor-health trap. This is, of course, a challenging issue. What would be the optimal policy? Increasing controls and sanctions lowers the size of the shadow economy at the cost of a decline in total employment due to the removal of informal jobs. As mentioned by Boeri et al. (2005), the reason informal employment is tolerated in emerging countries is that its repression would increase unemployment. Lowering taxation encourages informal firms to move to the formal sector but this may have damaging effects on the government budget (Cruces et al. (2010); Rocha et al. (2018)). Deregulating the product market may lead to similar results without a direct impact on fiscal revenue while generating potential risks to the health and safety of consumers. An alternative solution, proposed by Albertini and Terriau (2019a), involves subsidizing education. They show that the implementation of an educational grant reduces the informality rate and increases the employment rate. Moreover, for reasonable subsidy rates, this policy may be fully financed by the extra tax revenues generated by the increase in formal employment and wages. However, that study does not take into account the interaction between health and labor market trajectories over the life cycle. Further research is needed to analyze the role of human capital in health and labor outcomes and to 
provide appropriate policy recommendations.

\section{References}

Achdou, Y., Han, J., Lasry, J.-M., Lions, P.-L., and Moll, B. (2017). Income and Wealth Distribution in Macroeconomics: A Continuous-Time Approach. NBER Working Papers 23732, National Bureau of Economic Research, Inc.

Aiyagari, S. R. (1994). Uninsured idiosyncratic risk and aggregate saving. The Quarterly Journal of Economics, 109(3):659-684.

Albertini, J. and Terriau, A. (2019a). Informality over the life-cycle. Journal of Economic Dynamics and Control, 105:182-202.

Albertini, J. and Terriau, A. (2019b). Revisiting the nexus between health and poverty in south africa. Working Paper.

Albertini, J. and Terriau, A. (2019c). Wealth and health in south africa. GATE Working Paper Series WP 1911.

Alfers, L. and Rogan, M. (2015). Health risks and informal employment in south africa: does formality protect health? International journal of occupational and environmental health, 21(3):207-215.

Bagger, J., Fontaine, F., Postel-Vinay, F., and Robin, J.-M. (2014). Tenure, experience, human capital, and wages: A tractable equilibrium search model of wage dynamics. The American Economic Review, 104(6):15511596.

Boeri, T., Garibaldi, P., Hall, R. E., and Pissarides, C. A. (2005). Shadow sorting [with comments]. In NBER International Seminar on Macroeconomics, pages 125-170. JSTOR.

Burdett, K., Carrillo-Tudela, C., and Coles, M. G. (2011). Human capital accumulation and labor market equilibrium. International Economic Review, 52(3):657-677.

Burström, B. and Fredlund, P. (2001). Self rated health: Is it as good a predictor of subsequent mortality among adults in lower as well as in higher social classes? Journal of Epidemiology $\&$ Community Health, 55(11):836840. 
Connelly, J. E., Philbrick, J. T., Smith Jr, G. R., Kaiser, D. L., and Wymer, A. (1989). Health perceptions of primary care patients and the influence on health care utilization. Medical care, pages S99-S109.

Cruces, G., Galiani, S., and Kidyba, S. (2010). Payroll taxes, wages and employment: Identification through policy changes. Labour Economics, 17(4):743-749.

De Nardi, M. (2004). Wealth inequality and intergenerational links. The Review of Economic Studies, 71(3):743-768.

De Nardi, M., Pashchenko, S., and Porapakkarm, P. (2017). The lifetime costs of bad health. Technical report, National Bureau of Economic Research.

Dike, O. (2019). Informal employment and work health risks: Evidence from cambodia.

Franks, P., Gold, M. R., and Fiscella, K. (2003). Sociodemographics, self-rated health, and mortality in the us. Social science $\&$ medicine, 56(12):2505-2514.

French, E. (2005). The effects of health, wealth, and wages on labour supply and retirement behaviour. The Review of Economic Studies, 72(2):395427.

Frijters, P., Haisken-DeNew, J. P., and Shields, M. A. (2005). The causal effect of income on health: Evidence from german reunification. Journal of health economics, 24(5):997-1017.

Giatti, L., Barreto, S. M., and César, C. C. (2008). Household context and self-rated health: the effect of unemployment and informal work. Journal of Epidemiology $\&$ Community Health, pages jech-2007.

Gong, X., Van Soest, A., and Villagomez, E. (2004). Mobility in the urban labor market: a panel data analysis for mexico. Economic Development and Cultural Change, 53(1):1-36.

Grant, M. D., Piotrowski, Z. H., and Chappell, R. (1995). Self-reported health and survival in the longitudinal study of aging, 1984-1986. Journal of Clinical Epidemiology, 48(3):375-387.

Heckman, J. J. (1981). Heterogeneity and state dependence. In Studies in labor markets, pages 91-140. University of Chicago Press. 
Hendricks, L. (2007a). How important is discount rate heterogeneity for wealth inequality? Journal of Economic Dynamics and Control, 31(9):3042-3068.

Hendricks, L. (2007b). Retirement wealth and lifetime earnings. International Economic Review, 48(2):421-456.

Huggett, M. (1996). Wealth distribution in life-cycle economies. Journal of Monetary Economics, 38(3):469-494.

Hurlbut, W. B. (2018). Overcoming poverty and inequality in South Africa: An assessment of drivers, constraints and opportunities. World Bank.

Idler, E. L. and Angel, R. J. (1990). Self-rated health and mortality in the nhanes-i epidemiologic follow-up study. American journal of public health, 80(4):446-452.

Idler, E. L. and Benyamini, Y. (1997). Self-rated health and mortality: a review of twenty-seven community studies. Journal of health and social behavior, pages 21-37.

Idler, E. L. and Kasl, S. V. (1995). Self-ratings of health: do they also predict change in functional ability? The Journals of Gerontology Series B: Psychological Sciences and Social Sciences, 50(6):S344-S353.

Jones, A. M. and Schurer, S. (2011). How does heterogeneity shape the socioeconomic gradient in health satisfaction? Journal of Applied Econometrics, 26(4):549-579.

Krusell, P. and Smith, Jr, A. A. (1998). Income and wealth heterogeneity in the macroeconomy. Journal of political Economy, 106(5):867-896.

La Porta, R. and Shleifer, A. (2008). The unofficial economy and economic development. Technical report, National Bureau of Economic Research.

La Porta, R. and Shleifer, A. (2014). Informality and development. Journal of Economic Perspectives, 28(3):109-26.

LaRue, A., Bank, L., Jarvik, U., and Hetland, M. (1979). Health in old age: how do physicians' ratings and self-ratings compare? Journal of Gerontology, 34(5):687-691.

Loewenson, R. H. (1998). Health impact of occupational risks in the informal sector in zimbabwe. International Journal of Occupational and Environmental Health, 4(4):264-274. 
López-Ruiz, M., Artazcoz, L., Martínez, J. M., Rojas, M., and Benavides, F. G. (2015). Informal employment and health status in central america. BMC public health, 15(1):698.

Ludermir, A. B. and Lewis, G. (2003). Informal work and common mental disorders. Social psychiatry and psychiatric epidemiology, 38(9):485-489.

Lundberg, O. and Manderbacka, K. (1996). Assessing reliability of a measure of self-rated health. Scandinavian journal of social medicine, 24(3):218224.

McCallum, J., Shadbolt, B., and Wang, D. (1994). Self-rated health and survival: a 7-year follow-up study of australian elderly. American Journal of Public Health, 84(7):1100-1105.

Mossey, J. M. and Shapiro, E. (1982). Self-rated health: a predictor of mortality among the elderly. American journal of public health, 72(8):800808.

Okun, M. A., Stock, W. A., Haring, M. J., and Witter, R. A. (1984). Health and subjective well-being: A meta-analyis. The International journal of aging and human development, 19(2):111-132.

Pijoan-Mas, J. and Ríos-Rull, J.-V. (2014). Heterogeneity in expected longevities. Demography, 51(6):2075-2102.

Rocha, R., Ulyssea, G., and Rachter, L. (2018). Do lower taxes reduce informality? evidence from brazil. Journal of Development Economics, 134:28-49.

Romero, D. H. A., Oudin, A., Strömberg, U., Karlsson, J.-E., Welinder, H., Sequeira, G., Blanco, L., Jiménez, M., Sánchez, F., and Albin, M. (2010). Respiratory symptoms among waste-picking child laborers: a crosssectional study. International journal of occupational and environmental health, 16(2):120-131.

Ruiz, M. E., Vives, A., Martínez-Solanas, È., Julià, M., and Benach, J. (2017). How does informal employment impact population health? lessons from the chilean employment conditions survey. Safety science, 100:57-65.

Samwick, A. A. (1998). Discount rate heterogeneity and social security reform. Journal of Development Economics, 57(1):117-146.

Schneider, F. and Enste, D. H. (2000). Shadow economies: size, causes, and consequences. Journal of economic literature, 38(1):77-114. 
Van Doorslaer, E. and Gerdtham, U.-G. (2003). Does inequality in selfassessed health predict inequality in survival by income? evidence from swedish data. Social science \&f medicine, 57(9):1621-1629.

Venti, S. F. and Wise, D. A. (2000). Choice, chance, and wealth dispersion at retirement. Technical report, National Bureau of Economic Research. 


\section{A Survival probabilities}

Survival probabilities

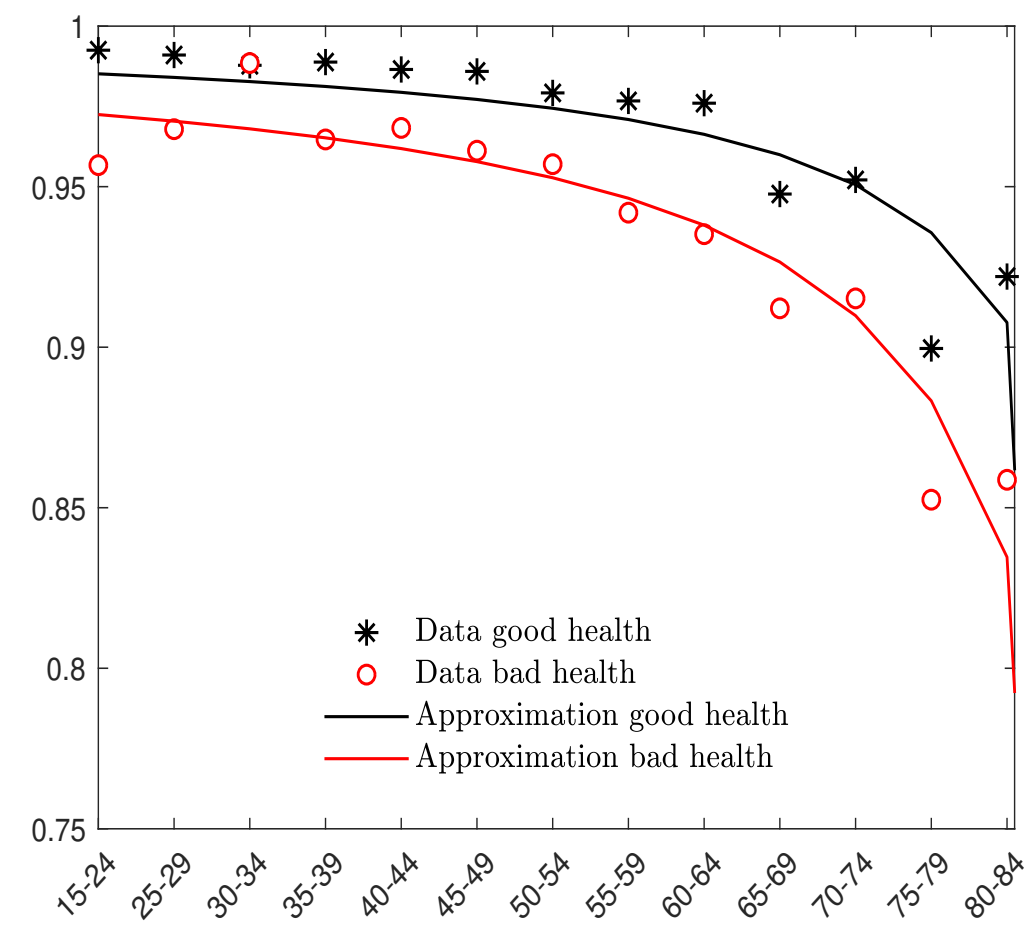

